\title{
The Impact of Plasma Membrane Lipid Composition on Flagellum-Mediated Adhesion of Enterohemorrhagic Escherichia coli
}

\author{
Hélène Cazzola, ${ }^{a}$ Laurine Lemaire, $^{a}$ Sébastien Acket, ${ }^{a}$ Elise Prost, ${ }^{a}$ Luminita Duma, $^{\mathrm{a}}$ (D) Marc Erhardt, ${ }^{\mathrm{b}}$ Petra Čechová, ${ }^{\mathrm{c}}$ \\ Patrick Trouillas, c,d Fady Mohareb,e Claire Rossi,, (D) Yannick Rossez ${ }^{\text {a }}$ \\ aUniversité de Technologie de Compiègne, UPJV, UMR CNRS 7025, Enzyme and Cell Engineering, Centre de recherche Royallieu, Compiègne, France \\ bInstitute for Biology-Bacterial Physiology, Humboldt_Universität zu Berlin, Berlin, Germany \\ cRCPTM, Palacký University Olomouc, Olomouc, Czech Republic \\ dINSERM U1248 —IPPRITT, University of Limoges, Limoges, France \\ eThe Bioinformatics Group, School of Water, Energy and Environment, Cranfield University, Cranfield, United Kingdom
}

Claire Rossi and Yannick Rossez equally supervised this work

ABSTRACT Enterohemorrhagic Escherichia coli (EHEC) O157:H7 is a major cause of foodborne gastrointestinal illness. The adhesion of EHEC to host tissues is the first step enabling bacterial colonization. Adhesins such as fimbriae and flagella mediate this process. Here, we studied the interaction of the bacterial flagellum with the host cell's plasma membrane using giant unilamellar vesicles (GUVs) as a biologically relevant model. Cultured cell lines contain many different molecular components, including proteins and glycoproteins. In contrast, with GUVs, we can characterize the bacterial mode of interaction solely with a defined lipid part of the cell membrane. Bacterial adhesion on GUVs was dependent on the presence of the flagellar filament and its motility. By testing different phospholipid head groups, the nature of the fatty acid chains, or the liposome curvature, we found that lipid packing is a key parameter to enable bacterial adhesion. Using HT-29 cells grown in the presence of polyunsaturated fatty acid ( $\alpha$-linolenic acid) or saturated fatty acid (palmitic acid), we found that $\alpha$-linolenic acid reduced adhesion of wild-type EHEC but not of a nonflagellated mutant. Finally, our results reveal that the presence of flagella is advantageous for the bacteria to bind to lipid rafts. We speculate that polyunsaturated fatty acids prevent flagellar adhesion on membrane bilayers and play a clear role for optimal host colonization. Flagellum-mediated adhesion to plasma membranes has broad implications for host-pathogen interactions.

IMPORTANCE Bacterial adhesion is a crucial step to allow bacteria to colonize their hosts, invade tissues, and form biofilm. Enterohemorrhagic Escherichia coli 0157:H7 is a human pathogen and the causative agent of diarrhea and hemorrhagic colitis. Here, we use biomimetic membrane models and cell lines to decipher the impact of lipid content of the plasma membrane on enterohemorrhagic E. coli flagellummediated adhesion. Our findings provide evidence that polyunsaturated fatty acid $(\alpha$-linolenic acid) inhibits $E$. coli flagellar adhesion to the plasma membrane in a mechanism separate from its antimicrobial and anti-inflammatory functions. In addition, we confirm that cholesterol-enriched lipid microdomains, often called lipid rafts, are important in bacterial adhesion. These findings demonstrate that plasma membrane adhesion via bacterial flagella play a significant role for an important human pathogen. This mechanism represents a promising target for the development of novel antiadhesion therapies.

Citation Cazzola H, Lemaire L, Acket S, Prost E, Duma L, Erhardt M, Čechová P, Trouillas P Mohareb F, Rossi C, Rossez Y. 2020. The impact of plasma membrane lipid composition on flagellum-mediated adhesion of enterohemorrhagic Escherichia coli. mSphere 5:e00702-20. https://doi.org/10.1128/mSphere $.00702-20$.

Editor Sarah E. F. D'Orazio, University of Kentucky

Copyright $\odot 2020$ Cazzola et al. This is an open-access article distributed under the terms of the Creative Commons Attribution 4.0 International license.

Address correspondence to Claire Rossi, claire.rossi@utc.fr, or Yannick Rossez, yannick.rossez@utc.fr.

Received 15 July 2020

Accepted 27 August 2020

Published 16 September 2020 
nterohemorrhagic Escherichia coli (EHEC) serotype 0157:H7 is a Shiga-toxinproducing strain characterized by peritrichous flagella and is responsible for major foodborne diseases and for serious infections (1). When ingested, infection with EHEC is characterized by symptoms ranging from hemorrhagic colitis to life-threatening complications (2). These bacteria have the capacity to infect and to multiply in a wide variety of host species, including humans, animals, and even plants (3). The persistence in their hosts, including humans, occurs through adhesion to tissues (4). EHEC adhere to the intestinal mucosa in a manner termed the attaching-and-effacing effect (5), but other mechanisms, involving flagella and pili, have been described but not fully characterized $(6,7)$. The pili are the most described adhesins present at the bacterial surface $(8,9)$. More recently, bacterial flagella have also been identified in bacterial adhesion on different host tissues (10-12). The bacterial flagellum is a multiprotein complex, best known as a filament responsible for bacterial movement toward preferred environmental niches (13). The presence of flagella can be seen as a characteristic marker of early-stage colonization.

The flagellum is mainly composed of a globular protein, the flagellin, which is organized in four connected domains named D0, D1, D2, and D3. Flagellin peptides fold back on themselves and the D0-D1 domains interact through a coiled-coil interface and hydrophobic contacts, which are essential in the flagellin polymerization process. These $\mathrm{N}$ - and C-terminal regions are well conserved across all bacterial flagellins. Conversely, the D2-D3 domains generate antigenic diversity and are exposed on the filament exterior $(14,15)$. These monomers form a helix made of 11 protofilaments of flagellin (16) with lengths up to 15 to $20 \mu \mathrm{m}$ and a diameter of around $20 \mathrm{~nm}$.

Recent evidence has suggested that flagella bind to the plasma membrane phospholipids mainly through hydrophobic effects $(17,18)$. However, little is known about the parameters that govern the direct interaction between the lipid bilayers of plasma membranes and the flagella of enteropathogenic bacteria. Previously, membrane rafts, which are membrane domains enriched in cholesterol and sphingolipids $(19,20)$, have been documented as targets of bacterial pathogens when targeting host membranes (21-24). To shed light on the impact of lipid composition and physical properties of the lipid bilayer on the adhesion of 0157:H7 flagella to the host cell's plasma membranes, we selected a series of biomimetic membranes to study the impact of phospholipid polar head group, lipid size, or fatty acid saturation. Various membrane parameters were tested, including fluidity, area per lipids, membrane thickness, and order parameters, by biophysical techniques and molecular dynamics (MD) simulations. Here, we demonstrate that bacterial flagella from EHEC 0157:H7 can bind to the cellular plasma membrane by exploiting membrane fluidity and head group packing. We further found that polyunsaturated fatty acids reduce flagellar adhesion and that lipid rafts promote flagellar adhesion.

\section{RESULTS}

Interactions of bacterial flagella with phosphatidylcholine vesicles. To expand our knowledge about bacterial flagellum adhesion on plasma membranes $(17,18)$, we initiated this study by visualizing the interaction of bacteria with biomimetic giant unilamellar vesicles (GUVs) composed mainly of phosphatidylcholine (PC) from eggs (egg-PC) at room temperature $\left(23^{\circ} \mathrm{C}\right)$. This was performed by combining fluorescence and phase-contrast microscopy. The lipid bilayer was doped with 2 mol\% of a greenemitting fluorescent phospholipid, namely, 1,2-dipalmitoyl-sn-glycero-3-phosphoethanolamine- $N$-(7-nitro-2-1,3-benzoxadiazol-4-yl) (NBD-PE) (Fig. 1A and B). The GUV average diameter was $6.27 \mu \mathrm{m}$, with diameters ranging from 2 to $41 \mu \mathrm{m}$ (calculated from more than 450 GUVs) (see Fig. S1 in the supplemental material). Such sizes are relevant with that of EHEC host cells (5 to $30 \mu \mathrm{m}$ in diameter). Following incubation with both nonflagellated and flagellated EHEC, the former bacteria were not easily found around the GUVs (Fig. 1A), whereas the latter were mainly observed around the GUVs (Fig. 1B). 




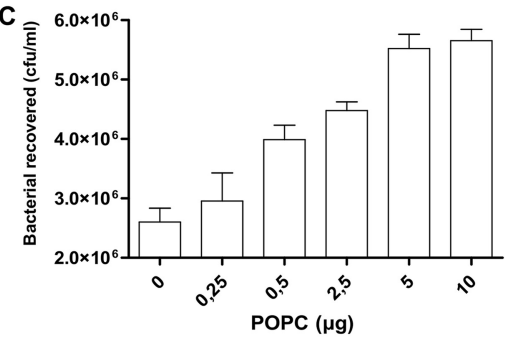

D

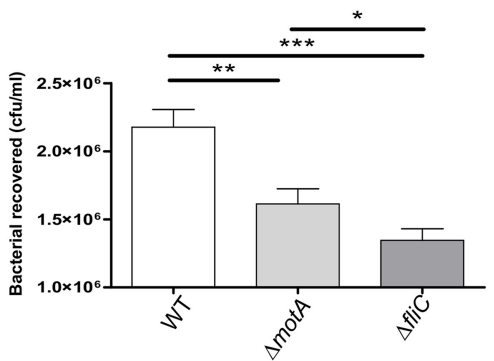

FIG 1 Interaction of egg-PC (GUV) with EHEC 0157:H7. View of the liposome surface after immobilization (doped with $2 \mathrm{~mol} \%$ NBD-PE) EHEC $\triangle$ fliC (A) and EHEC WT (B). Bacteria are visible in phase contrast. Red circles show bacteria around the GUV. (C) Interaction of the same bacterial concentration on different lipid vesicle quantities $(0$, $0.25,0.5,2.5,5$, and $10 \mu \mathrm{g}$ ). $n=9$ biologically independent samples. (D) Adhesion of EHEC WT, $\Delta$ mot $A$, and $\Delta$ fliC strains. Nonspecific adhesion on plastic was subtracted. WT, $n=51 ; \Delta \operatorname{mot} A, n=31 ; \Delta$ flic, $n=18$ biologically independent samples. The bar graphs present the means of the reported data. Statistical significances were determined by a two-tailed Student's $t$ test. ${ }^{* *}, P \leq 0.001 ;{ }^{* *}, P \leq 0.005 ;{ }^{*}, P \leq 0.05$.

The Brownian motion of GUVs and the motility of bacteria make the interaction between the two species difficult to quantify by microscopy. Therefore, we used a quantitative binding assay on GUVs as described previously (18) and illustrated in Fig. S2.

The lipid quantity immobilized on the GUV surface was dose dependent (Fig. 1C). A lipid GUV suspension containing from 0 to $10 \mu \mathrm{g}$ of PC was deposited onto the gold surface and subsequently incubated with EHEC. An increase of adherent bacteria was observed up to $5 \mu \mathrm{g}$. This plateau means that saturation of bacterial adhesion was achieved under the experimental conditions. As a result, all the other experiments were performed with $5 \mu \mathrm{g}$ of GUVs.

Both the presence of the flagella and their motility was assessed to understand the role of flagella in bacterial adhesion. The comparison between EHEC wild type (WT) and the flagella-free EHEC mutant $(\triangle f l i C$ ) confirmed that the lack of flagella is responsible for less-adherent bacteria (Fig. 1D). A nonmotile but flagellated EHEC mutant $(\triangle \operatorname{mot} A)$ was also studied. EHEC $\triangle m$ motA was more adherent than the $\triangle f l i C$ mutant (Fig. 1D), suggesting that the flagellar movement plays a role in bacterial adhesion. Collectively, these results confirmed the suitability of the GUV adhesion assay to investigate the adhesive properties of EHEC flagella and reveal a key role of bacterial flagella and active motility in the adhesion process on plasma membrane lipid bilayers.

Role of vesicle curvature in flagellar adhesion. To tackle the impact of curvature on flagellar adhesion, large unilamellar vesicles (LUVs) were produced with a diameter of $400 \pm 30 \mathrm{~nm}$. Surprisingly, EHEC cells were less adherent on LUVs than on GUVs (Fig. 2A), suggesting an impact of the size of the vesicles, thus, membrane curvature, on flagellar adhesion. To further investigate vesicle curvature dependence, generalized polarization (GP) measurements were performed with laurdan (6-dodecanoyl-2-dimethylaminonaphthalene), an amphiphilic fluorescent dye sensitive to local packing. Because laurdan GP sensed changes in the phospholipid order $(25,26)$, if the bacterial flagella penetrated the plasma membrane, a lower GP order would be observed (Fig. 2B). Vesicles with different sizes were incubated with purified $\mathrm{H} 7$ flagella to investigate the impact of four different bilayer curvatures. The GP measurement could not be performed on the whole bacterium, because the 


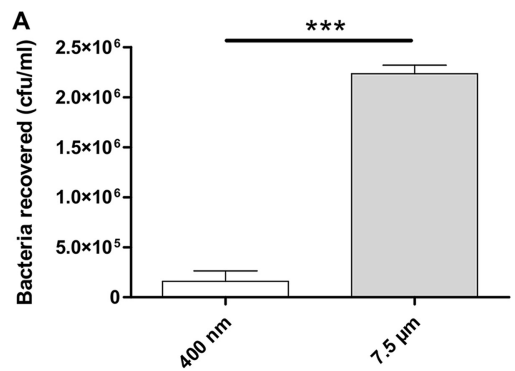

B

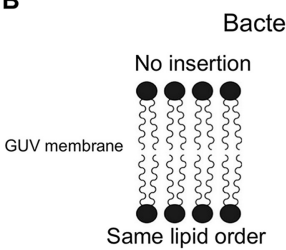

Bacteri

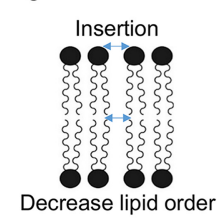

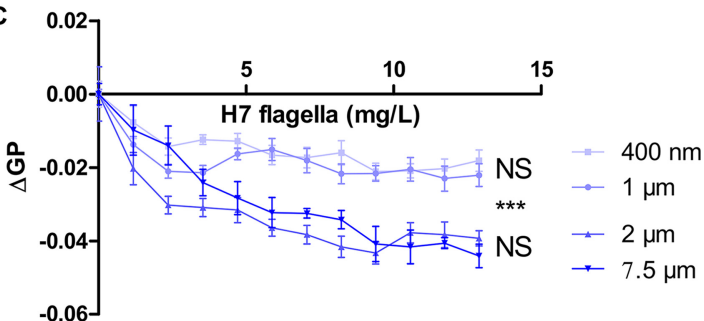

FIG 2 Bacterial flagellar adhesion and lipid vesicle curvature. (A) EHEC WT adhesion on phosphatidylcholine (egg-PC) GUVs $(7.5 \mu \mathrm{m})$ and LUVs ( $\sim 400-\mathrm{nm}$ diameter). Nonspecific adhesion on plastic was subtracted. $400 \mathrm{~nm}$, $n=18 ; 7.5 \mu \mathrm{m}, n=51$ biologically independent samples. (B) Scheme of the principle of the generalized polarization (GP) measurements. (C) Relative laurdan emission ( $\triangle \mathrm{GP}$ ) was calculated by successive addition of purified $\mathrm{H} 7$ flagella in solution containing different sizes of phosphatidylcholine (egg-PC) liposomes at $37^{\circ} \mathrm{C}$. For each concentration, at least $n=5$ biologically independent samples were used. Statistical significances were determined by a two-tailed Student's $t$ test and were calculated at the highest concentration of $\mathrm{H} 7$ flagella. The graphs present the means of the reported data. ${ }^{* *}, P \leq 0.001$; NS, not significant.

probe detects mainly the bacterial motility in the surrounding environment of the vesicles (data not shown). As the initial packing of the lipid bilayers depends on the curvature, the initial GP value of the vesicles with different diameters was normalized by subtracting the GP value in the absence of flagella for each size of liposome $(\Delta G P)$ (Fig. 2C). The presence of $\mathrm{H} 7$ with vesicles allowed slight changes in the lipid order only for vesicle diameters greater than $2 \mu \mathrm{m}$. This confirms the existence of a threshold diameter above which the interaction becomes significant.

Role of phospholipid head groups in flagellar adhesion. We next evaluated more thoroughly how different lipid species may affect EHEC flagellar adhesion. Focus was first given to the influence of the lipid head groups, as they could modulate bilayer curvature and lipid packing (27). Since our first results were obtained with vesicles composed of egg-PC, we characterized precisely the fatty acid profile and the lipid species of the egg-PC that we used by gas chromatography-flame ionization detection (GC-FID) and liquid chromatography-mass spectrometry (LC-MS), respectively. The main fatty acids were $C_{16: 0}$ (palmitic acid), $C_{18: 0}$ (stearic acid), $C_{18: 1}$ (oleic acid), and $C_{18: 2}$ (linoleic acid). PC 34:1, composed of palmitic acid and oleic acid, named 1-palmitoyl2-oleoyl phosphatidylcholine (POPC) was the most abundant lipid (Fig. S3).

In the following experiments, membranes made of POPC alone were compared to membranes made of POPC associated with other two phospholipids found in host plasma membrane with the same fatty acid composition: 1-palmitoyl-2-oleoyl-snglycero-3-phosphoethanolamine (POPE) and 1-palmitoyl-2-oleoyl-sn-glycero-3-phospho-(1'-rac-glycerol) (POPG). To prevent destabilization of the bilayer, POPG and POPE were mixed with POPC at $60 \mathrm{~mol} \%$ (28). This allowed tackling the influence of the lipid head groups, which is known to impact various bilayer's properties, including curvature or lipid packing (29). Like POPC, POPE is zwitterionic but has a negative curvature. Conversely, POPG carries a negative charge at physiological pH and exhibits a zero spontaneous curvature, like POPC (30).

A clear reduction of adhering bacteria was observed when POPC was mixed with POPE or POPG (Fig. 3A). To unravel the role of membrane fluidity, membrane thicknesses and areas per lipid were calculated from MD simulations. The presence of POPE 
A

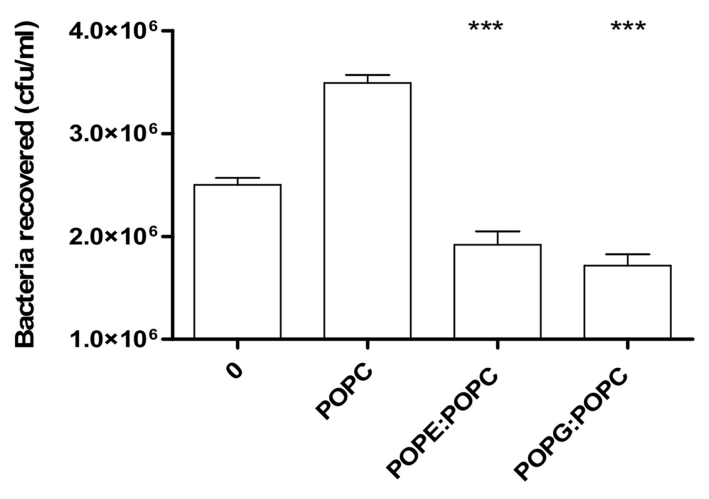

C

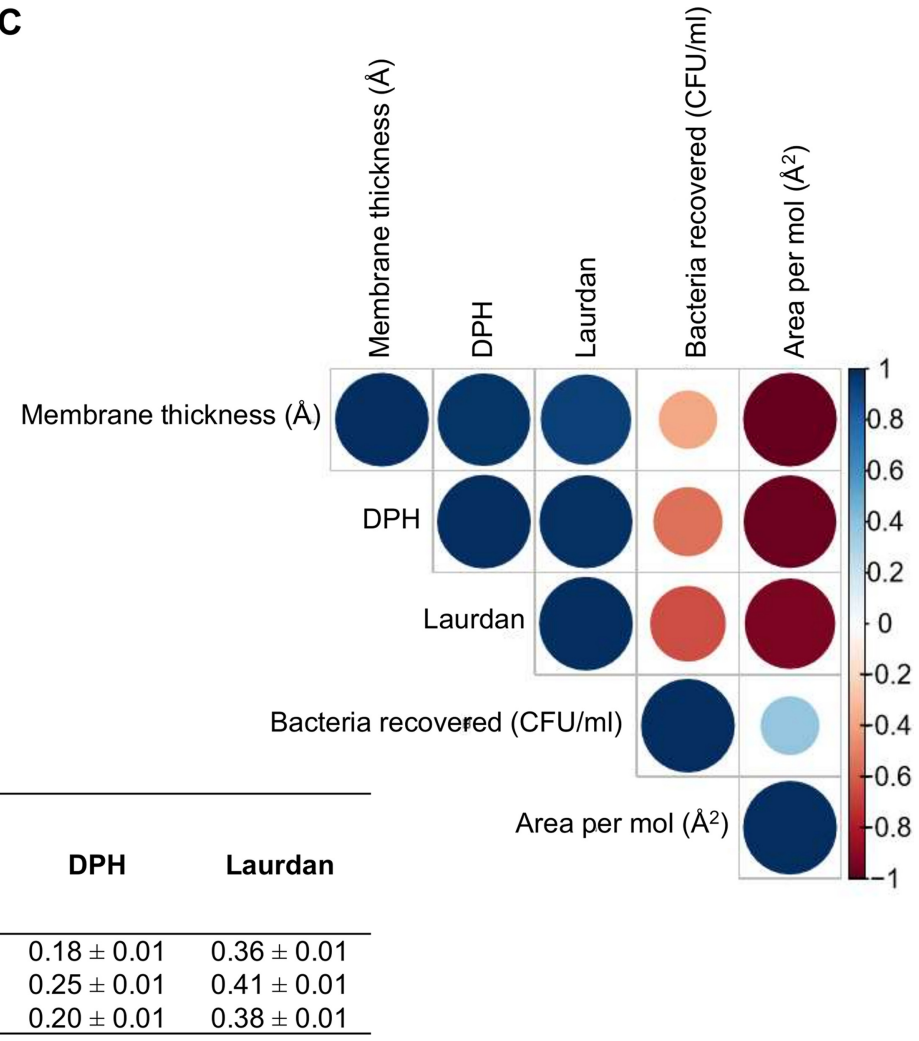

FIG 3 Impact of head polar phospholipids with one palmitic $\left(C_{16: 0}\right)$ and one oleic $\left(C_{18: 1}\right)$ acid (PO) on EHEC flagellar adhesion. $(A)$ EHEC adhesion on PO acyl chain lipids. 0 corresponds to the naked gold-coated glass surface. POPC/POPE and POPC/POPG were mixed 40:60 mol. Nonspecific adhesion on plastic was subtracted. $0, n=135$; POPC, $n=25$; POPC/POPE, $n=12$; POPC/POPG, $n=23$ biologically independent samples. The bar graph presents the means of the reported data. Statistical significances were determined by a two-tailed Student's $t$ test. ${ }^{* *}, P \leq 0.001$. (B) Table summarizing anisotropy values for diphenylhexatriene (DPH) and laurdan probes at $23^{\circ} \mathrm{C}$. The averages and standard deviations were calculated from at least three independent measurements. Membrane thickness and area per molecule, as well as related standard deviations, were calculated over the last 200 ns of MD simulations. (C) Correlogram representing Pearson's correlation coefficients calculated for bacteria recovered, membrane thickness, area per mol, and diphenylhexatriene (DPH) and laurdan anisotropies for the following lipids: POPC, POPC/POPE, POPC/POPG. Positive correlations are shown in blue while negative correlations are in red. The color intensity and the size are proportional to the correlation coefficients. (Right) Legend shows the correlation coefficients and the corresponding colors. More detailed information on the significance of the correlations and on the correlation coefficients can be found in Fig. S4 in the supplemental material.

dramatically affected these membrane properties by decreasing the area per lipid and increasing membrane thickness. In other words, POPE increased ordering, as also seen by the order parameters of lipids in the POPE/POPC binary mixture with respect to the pure POPC bilayer (Fig. 3B). Conversely, the presence of POPG only slightly affected the area per lipid and increased membrane thickness. To further investigate membrane ordering, steady-state fluorescence anisotropy measurements were performed on GUVs (Fig. 3B) using two probes, diphenylhexatriene (DPH) and laurdan (28). Their partitioning allows the monitoring of lipid dynamics in different membrane regions. The amphiphilic structure of laurdan is localized at the hydrophobic-hydrophilic interface region, whereas DPH locates to the hydrophobic core of the lipid bilayer (31).

As expected and already described in the literature (32), membrane thickness and area per lipid are negatively correlated. In addition, these parameters correlated with the fluidity values (Fig. 3C), showing a very high positive correlation between the two-bilayer order parameters. Furthermore, bacterial adhesion decreased when fluidity increased with a correlation coefficient ranging from -0.54 (for DPH values) to -0.65 (for laurdan values). This correlation was clearly evidenced, since POPC and POPE exhibit strong differences in their membrane properties, thicknesses, and areas per lipid (Fig. 3B). Conversely, the differences between POPC and POPG are much smaller; however, they are differently charged.

To further study the impact of the polar head group, a series of lipid bilayers made of two cis-oleic acid moieties, namely, 1,2-dioleoyl-sn-glycero-3-phosphocholine 
A

\begin{tabular}{lccccc}
\cline { 2 - 6 } & $\begin{array}{c}\text { Membrane } \\
\text { thickness } \\
{[\mathbf{A}]}\end{array}$ & $\begin{array}{c}\text { Area per } \\
\text { mol } \\
{\left[\AA^{2}\right]}\end{array}$ & $\begin{array}{c}\text { Dominant } \\
\text { charge at } \\
\text { physiological } \\
\text { pH }\end{array}$ & DPH & Laurdan \\
\cline { 2 - 6 } DOPC & $40.1 \pm 0.6$ & $64.1 \pm 1.0$ & $+/-$ & $0.16 \pm 0.01$ & $0.36 \pm 0.01$ \\
POPC:DOPC & $40.7 \pm 0.7$ & $61.9 \pm 1.3$ & $+/-$ & $0.19 \pm 0.01$ & $0.38 \pm 0.01$ \\
POPC:DOPE & $42.9 \pm 0.8$ & $56.8 \pm 1.3$ & $+/-$ & $0.19 \pm 0.01$ & $0.38 \pm 0.01$ \\
POPC:DOPG & $40.1 \pm 0.7$ & $62.6 \pm 1.2$ & - & $0.18 \pm 0.01$ & $0.37 \pm 0.01$ \\
POPC:DOTAP & ND & ND & + & $0.17 \pm 0.01$ & $0.36 \pm 0.01$ \\
\cline { 2 - 6 }
\end{tabular}

B

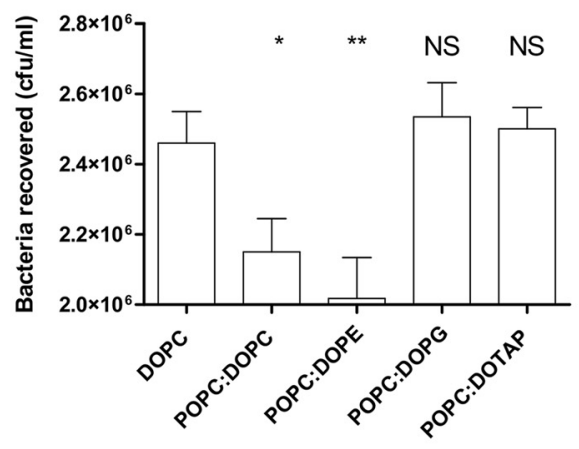

C

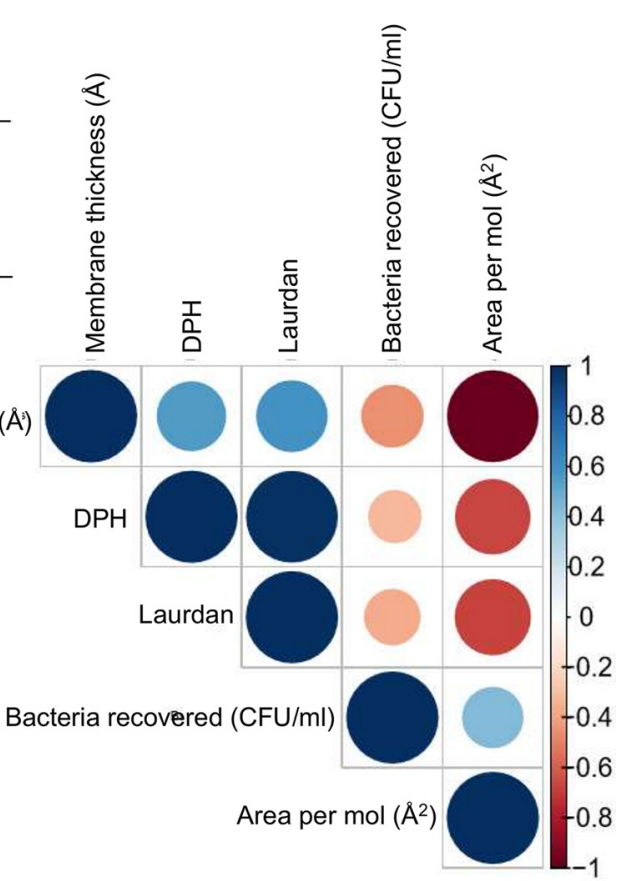

FIG 4 Impact of head polar phospholipids with two oleic acids $\left(C_{18: 1}\right)$ (DO) on EHEC flagellar adhesion. (A) Table summarizing anisotropy values for diphenylhexatriene (DPH) and laurdan probes at $23^{\circ} \mathrm{C}$. The averages and standard deviations were calculated from at least three independent measurements. Membrane thickness and area per molecule, as well as related standard deviations, were calculated over the last $200 \mathrm{~ns}$ of MD simulations. (B) EHEC adhesion on DO acyl chain lipids. All mixture compositions, except for DOPC, were POPC/X 40:60 mol\%, with $X$ the second lipid. Nonspecific adhesion on plastic was subtracted. DOPC, $n=13$; POPC/DOPC, $n=10$; POPC/DOPE, $n=19$; POPC/DOPG, $n=12$; POPC/DOTAP, $n=17$ biologically independent samples. The bar graph presents the means of the reported data. Statistical significances were determined by a two-tailed Student's $t$ test. ${ }^{* *}, P \leq 0.005 ;{ }^{*}, P \leq 0.05 ; \mathrm{NS}$, not significant. (C) Correlogram representing Pearson's correlation coefficients calculated for bacteria recovered, membrane thickness, area per mol, and DPH and laurdan anisotropies for the following lipids: DOPC, POPC/DOPC, POPC/DOPE, and POPC/DOPG. Positive correlations are shown in blue, while negative correlations are in red. The color intensity and the size are proportional to the correlation coefficients. (Right) Legend shows the correlation coefficients and the corresponding colors. More detailed information on the significance of the correlations and on the correlation coefficients can be found in Fig. S5.

(DOPC), 1,2-dioleoyl-sn-glycero-3-phosphoethanolamine (DOPE), and 1,2-dioleoyl-snglycero-3-phospho-(1'-rac-glycerol) (DOPG), was selected. Due to the presence of one unsaturation per lipid chain, the lipid order was significantly decreased compared to that of the PO series, i.e., greater membrane areas per lipid and lower order parameters (Fig. 4A). As a consequence of this global disordering effect, the variations in the lipid order were smoothed within the DOPC, DOPE, and DOPG series with respect to those in the PO series, allowing a better focus on the sheer impact of the chemical feature and charge of the head groups. A synthetic positively charged lipid was also added: 1,2-dioleoyl-3-trimethylammonium-propane (DOTAP). The three lipids, DOPE, DOPG, and DOTAP, were mixed with POPC at 40:60 molar ratio. Fewer bacteria were recovered on DOPC $\left(\sim 2.5 \times 10^{6} \mathrm{CFU} / \mathrm{ml}\right)$ alone than with POPC $\left(\sim 3.0 \times 10^{6} \mathrm{CFU} / \mathrm{ml}\right)$ (Fig. $\left.4 \mathrm{~B}\right)$. When mixing POPC with DOPC or DOPE, this number was significantly lower than for DOPC alone. Interestingly, we observed no significant differences either with DOPG or with DOTAP mixed with POPC with respect to pure DOPC (Fig. 4B). The bacterial adhesion had a low negative correlation except for the area per lipid parameter, which was positive (Fig. 4C). An impact of the head group charge was observed on EHEC flagellum adhesion. Zwitterionic phospholipids for the DO bilayer series decreased bacterial adhesion, and conversely, negative and positive head groups had no impact. We thus reasoned that lipid charge and membrane properties could differentially affect flagellar adhesion to plasma membrane lipids driven in part by the acyl chain content.

Role of phospholipid acyl chains in flagellar adhesion. To investigate further the impact of phospholipid unsaturation, directly related to the fluidity, on bacterial adhesion, the membrane parameters were assessed in the subsequent series: pure 
A

\begin{tabular}{|c|c|c|c|c|c|}
\hline & $\begin{array}{c}\text { Membrane } \\
\text { thickness } \\
{[\hat{A}]} \\
\end{array}$ & $\begin{array}{c}\text { Area per } \\
\text { mol } \\
{\left[\AA^{2}\right]}\end{array}$ & $\begin{array}{c}\text { Transition } \\
\text { temperature } \\
\left(\mathrm{Tm},{ }^{\circ} \mathrm{C}\right)\end{array}$ & DPH & Laurdan \\
\hline DOPC cis & $40.1 \pm 0.6$ & $64.1 \pm 1.0$ & $-18.3 \pm 3.6$ & $0.16 \pm 0.01$ & $0.36 \pm 0.01$ \\
\hline DOPC trans & ND & ND & $11.9 \pm 1.0$ & $0.17 \pm 0.01$ & $0.36 \pm 0.01$ \\
\hline DOPC trans $4^{\circ} \mathrm{C}$ & ND & ND & $11.9 \pm 1.0$ & $0.19 \pm 0.01$ & $0.45 \pm 0.01$ \\
\hline \multirow{2}{*}{$\begin{array}{l}\text { PC 18:3 } \\
\text { PC 18:2/18:3 } \\
\text { PC 18:2 }\end{array}$} & $\begin{array}{c}\text { ND } \\
38.7 \pm 0.6\end{array}$ & $\begin{array}{c}\text { ND } \\
65.2 \pm 1.3\end{array}$ & $\begin{array}{c}-61.5 \pm 2.1 \\
N D\end{array}$ & $\begin{array}{c}0.13 \pm 0.01 \\
N D\end{array}$ & $\begin{array}{c}0.33 \pm 0.01 \\
\text { ND }\end{array}$ \\
\hline & ND & ND & $-55.1 \pm 2.8$ & $0.14 \pm 0.01$ & $0.34 \pm 0.01$ \\
\hline
\end{tabular}

B



Bacteria recovered (CFU/ml)

FIG 5 Impact of fatty acids with phosphatidylcholine (PC) head group on EHEC flagellar adhesion. (A) Table summarizing anisotropy values for diphenylhexatriene (DPH) and laurdan probes at $23^{\circ} \mathrm{C}$ and transition temperatures based on reference 84 . The averages and standard deviations were calculated from at least three independent measurements. Membrane thickness and area per molecule, as well as related standard deviations, were calculated over the last 200 ns of MD simulations. (B) EHEC adhesion on PC with different fatty acid compositions. All lipids were tested pure. Nonspecific adhesion on plastic was subtracted. $D O P C$ cis $\left(C_{18: 1} / C_{18: 1}\right), n=13 ; P O P C$ $\left(C 1_{6: 0} / C_{18: 1}\right), n=25$; DOPC trans $\left(C_{18: 1} C_{18: 1}\right), n=13$; DOPC trans $4^{\circ} \mathrm{C}\left(C_{18: 1} / C_{18: 1}\right), n=15 ; P C 18: 3, n=11$ biologically independent samples. The bar graph presents the means of the reported data. Statistical significances were determined by a two-tailed Student's $t$ test. ${ }^{* * *}, P \leq 0.001 ;{ }^{*}, P \leq 0.05$; NS, not significant. (C) Correlogram representing Pearson's correlation coefficients calculated for bacteria recovered, membrane thickness, area per mol, and DPH and laurdan anisotropies for the following lipids: DOPC cis, POPC, POPC/DOPC (from Fig. 4), PC 18:3 ( $\alpha$-linolenic acid), and PC 18:2 (linoleic acid) at $23^{\circ} \mathrm{C}$. For PC 18:3, membrane thickness and area per molecules are from PC 18:2. The other parameters are from PC 18:3. Positive correlations are shown in blue, while negative correlations are in red. The color intensity and the size are proportional to the correlation coefficients. (Right) Legend shows the correlation coefficients and the corresponding colors. More detailed information on the significance of the correlations and on the correlation coefficients can be found in Fig. S7.

POPC, DOPC $\triangle 9$-cis (DOPC cis), DOPC $\triangle 9$-trans (DOPC trans), and a polyunsaturated lipid, PC 18:3/18:3 (PC 18:3). All lipids were tested at room temperature as before $\left(23^{\circ} \mathrm{C}\right)$, because as long as we worked at a temperature above their phase transition temperature $\left(T_{m}\right)$, no changes were introduced to the ordered gel phase. DOPC trans was also tested at $4^{\circ} \mathrm{C}$, as it has a phase $T_{m}$ of $12^{\circ} \mathrm{C}$. Namely, at $23^{\circ} \mathrm{C}$, all lipids were in fluid (disordered) phase (Fig. 5A), whereas at $4^{\circ} \mathrm{C}$, the bilayer made of DOPC trans was ordered. At $23^{\circ} \mathrm{C}$, GUVs made of $100 \%$ DOPC exhibited less bacterial adhesion than those from the POPC membrane, regardless of whether the double bond was in trans or cis (Fig. 5B). This is in line with their anisotropy under the same temperature condition. At $4^{\circ} \mathrm{C}$, DOPC trans was ordered and fewer bacteria were stuck on it. Interestingly, the presence of two $\alpha$-linolenic acids in the PC 18:3 drastically decreased adhesion, most probably because of a dramatic change in their fluidity and area per lipid, thus, ordering. These results indicate that membrane fluidity can affect flagellar adhesion, and extreme values ( 0.19 and 0.13 with $\mathrm{DPH}$; and 0.33 and 0.45 with laurdan) are not in favor of adhesion. The positive correlations between EHEC adhesion and the fluidity state of the bilayers for POPC, DOPC cis, DOPC trans, and PC $18: 3$ at $23^{\circ} \mathrm{C}$ were between high and very high (see Fig. S6), indicating that the more fluid the membrane, the lower the bacterial interaction with the GUV membrane. A correlation was performed to include all parameters (anisotropy values and values obtained by MD simulations) when available, in order to compare the same head group with different fatty acids (Fig. 5C). DOPC cis, POPC, POPC-DOPC and PC 18:2/18:3 at $23^{\circ} \mathrm{C}$ were included. We must note here that bacterial adherence assays were obtained with $P C$ 18:3, although MD simulation values were determined with PC 18:2/18:3. The former 

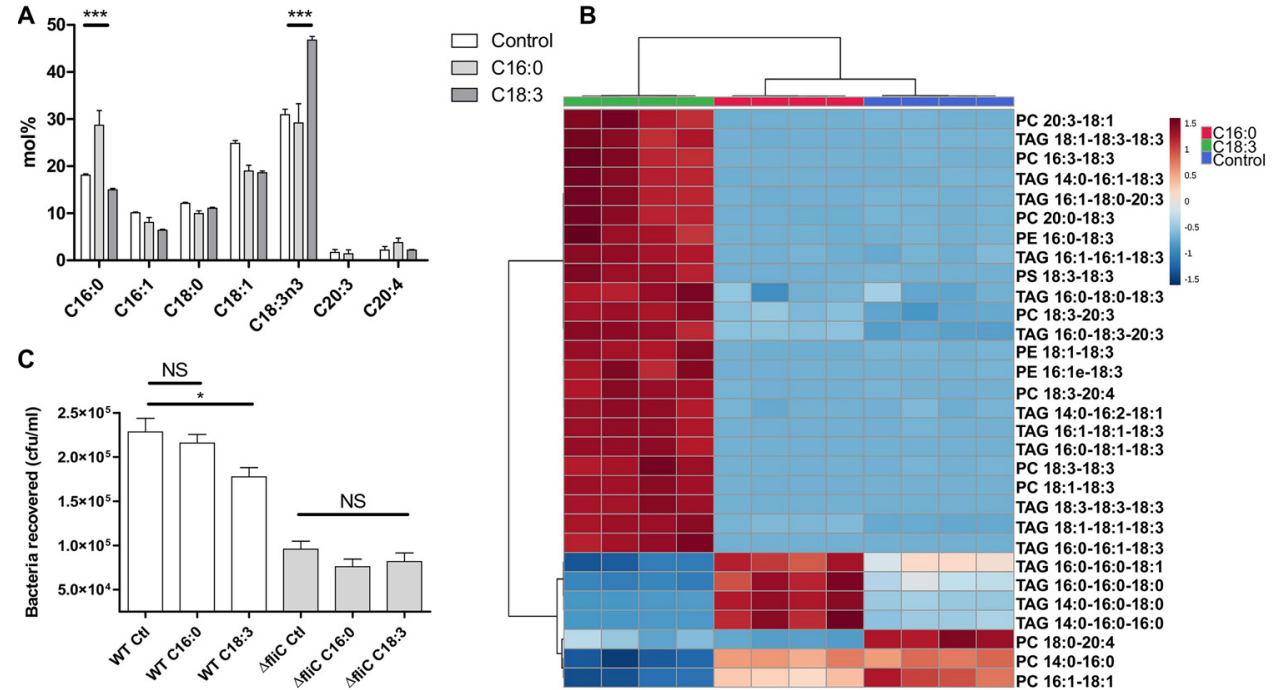

FIG 6 Modulation of fatty acid content in HT-29 and effect on EHEC adhesion. (A) Fatty acid methyl ester analysis of HT-29 cells by GC-FID, according to their diet: ethanol (control), $\mathrm{C}_{16: 0}$ or $\mathrm{C}_{18: 3} . n=4$ biologically independent samples. Statistical significances were determined by a two-tailed Student's $t$ test. (B) Heat map of the 30 most statistically different lipids species (right) analyzed by LC-MS comparing the control (ethanol, blue) and palmitic acid-treated $\left(C_{16: 0}\right.$, red) and $\alpha$-linolenic acid-treated $\left(C_{18: 3}\right.$, green) cells. Color coding indicates greater deviation from the mean from all samples for a particular lipid. The analysis was performed using MetaboAnalyst V4.0. (C) Adhesion of EHEC WT and $\triangle$ fliC strains on HT-29 after the different treatments. $n=12$ biologically independent samples. The bar graphs present the means of the reported data. Statistical significances were determined by a two-tailed Student's $t$ test. ${ }^{* *}, P \leq 0.001 ;{ }^{*}, P \leq 0.05$; NS, not significant.

lipid is not available in simulation databases, whereas the latter lipid has already been parameterized in the Charmm force field. These two lipids are structurally very close (same head group and only one difference in unsaturation), and very similar behaviors of the lipid bilayers are likely (33). Moreover, anisotropy values were measured for PC 18:2/18:2 (PC 18:2), and no difference was observed compared to those for PC 18:3 (Fig. 5C). All correlations between bacterial adhesion numbers and the other parameters were high except those for laurdan anisotropy, which were moderate. To favor more adhering bacteria with pure PC GUVs, the membrane thickness needs to be around $40 \AA$ and the area per molecule should be $60 \AA$. A thinner plasma membrane and too much space between molecules do not help bacterial adhesion. These results are directly linked to those for membrane fluidity.

Interactions of bacterial flagella with cell lines and lipid rafts. To provide further evidence about the impact of lipid composition with physiological membranes, colon epithelial cells (HT-29) enriched in saturated (palmitic acid) or unsaturated ( $\alpha$-linolenic acid) fatty acids were used. The lipid content of treated HT-29 cells was evaluated by GC-FID (Fig. 6A), which confirmed enrichment in both palmitic and $\alpha$-linolenic acids. An LC-MS analysis confirmed these results and showed an accumulation of palmitic acid and linolenic acid when treated with the corresponding fatty acid (Fig. 6B). Palmitic acid was more incorporated into intracytoplasmic lipid droplets through triglycerides (TAG) than polyunsaturated fatty acid ( $\alpha$-linolenic acid, $\left.C_{18: 3}\right)(34)$. Linolenic acid was found as well in molecular species associated with the plasma membrane (phospholipids). This result was described earlier with another human colon cell line (Caco-2 cells) (35). After the cells were washed, they were incubated with EHEC WT or a $\triangle$ fliC mutant for $30 \mathrm{~min}$. As with biomimetic membranes, significantly fewer bacteria adhered to HT-29 cells treated with $\alpha$-linolenic acid, probably because of the effect of this fatty acid on plasma membrane fluidity. This result was observed only when EHEC cells were flagellated, highlighting the role of flagella in the adhesion process (Fig. 6C), with a significant impact of membrane fluidity on the strength of flagellum-membrane binding.

Based on these observations, we next addressed the role of plasma membrane fluidity with membrane models mimicking lipid rafts, as they have been suggested 
A

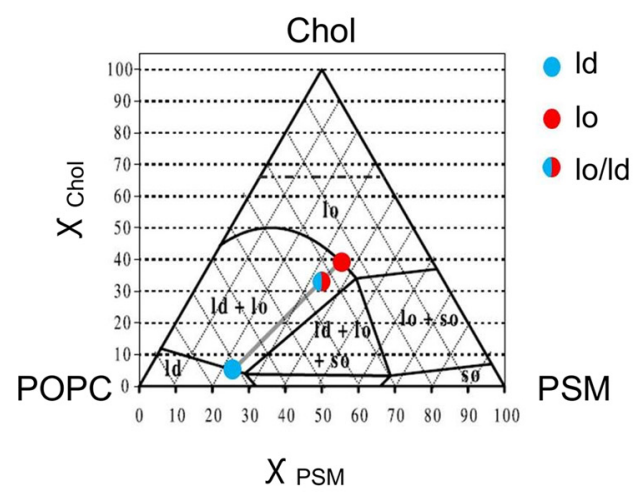

C

\begin{tabular}{lcccc}
\cline { 2 - 5 } & $\begin{array}{c}\text { Membrane } \\
\text { thickness } \\
{[\AA \tilde{A}]}\end{array}$ & $\begin{array}{c}\text { Area per } \\
\text { mol } \\
{\left[\AA^{2}\right]}\end{array}$ & DPH & Laurdan \\
\cline { 2 - 5 } & $40.7 \pm 0.6$ & $60.0 \pm 1.1$ & $0.18 \pm 0.01$ & $0.36 \pm 0.01$ \\
POPC & $45.6 \pm 0.4$ & $48.9 \pm 0.5$ & $0.22 \pm 0.01$ & $0.38 \pm 0.01$ \\
Id & $47.3 \pm 0.3$ & $40.2 \pm 0.3$ & $0.36 \pm 0.01$ & $0.42 \pm 0.01$ \\
lo & $47.9 \pm 0.3$ & $40.3 \pm 0.3$ & $0.34 \pm 0.01$ & $0.4 \pm 0.01$ \\
lo/ld & & &
\end{tabular}

\section{B}

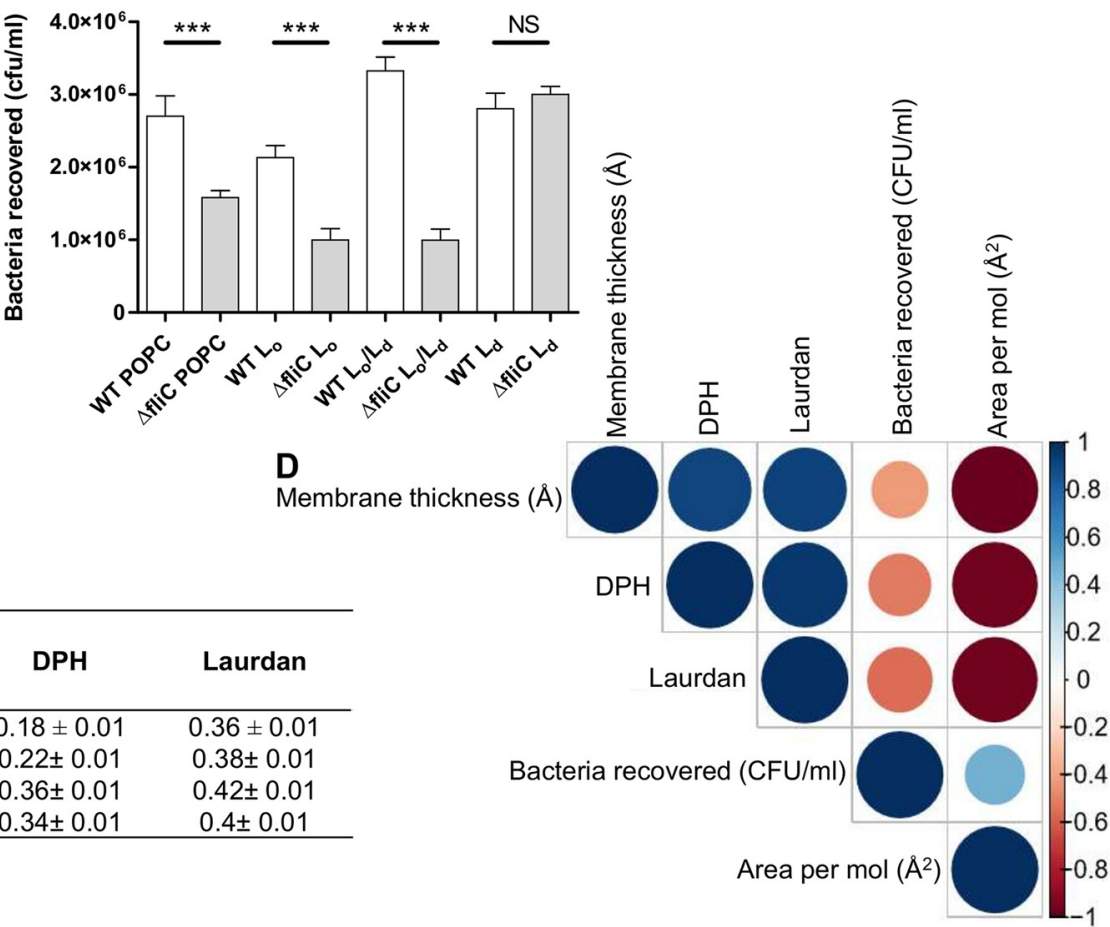

FIG 7 EHEC adhesion and lipid rafts. (A) POPC/PSM/chol phase diagram at $23^{\circ} \mathrm{C}$ adapted from reference 37 . The dashed horizontal line for $x$ Chol 0.66 represents the cholesterol solubility limit on the lipid bilayer. (B) Adhesion of EHEC WT and $\triangle$ fliC strains on three different lipid mixes from the ternary lipid system (POPC/PSM/chol). $n=36$ biologically independent samples for all $\Delta$ fliC and WT strains, except for WT lo/ld, $n=30$ biologically independent samples. The bar graph presents the means of the reported data. Statistical significances were determined by a two-tailed Student's $t$ test. ${ }^{* * *}, P \leq 0.001$; NS, not significant. Nonspecific adhesion on plastic was subtracted. The averages and standard deviations were calculated from three independent experiments. ( $C$ ) Table summarizing anisotropy values for diphenylhexatriene (DPH) and laurdan probes at $23^{\circ} \mathrm{C}$. The averages and standard deviations were calculated from at least three independent measurements. Membrane thickness and area per molecule, as well as related standard deviations, were calculated over the last 200 ns of MD simulations. (D) Correlogram representing Pearson's correlation coefficients calculated for bacteria recovered, membrane thickness, area per mol, and DPH and laurdan anisotropies for the following lipids: POPC, Id, lo, and lo/ld. Positive correlations are shown in blue, while negative correlations are in red. The color intensity and the size are proportional to the correlation coefficients. (Right) Legend color shows the correlation coefficients and the corresponding colors. More detailed information on the significance of the correlations and on the correlation coefficients can be found in Fig. S8.

to play a role in bacterial adhesion $(21,36)$ or in $E$. coli flagellar adhesion (22) to epithelial cells. Three lipids were used for these experiments: POPC, cholesterol (chol), and palmitoyl sphingomyelin (PSM). This ternary lipid system is a model for lipid rafts with a phase diagram established at $23^{\circ} \mathrm{C}$ (37). The ratios of the three lipids were set so that three different lipid orders were obtained, namely, the liquid ordered (lo) (POPC) $\mathrm{PSM} / \mathrm{chol}$, 24.87:36.00:39.13 molar ratio), liquid disordered (Id) (POPC/PSM/chol, 71.53: 23.25:5.22 molar ratio), and a mixed lo/ld system (POPC/PSM/chol, 1:1:1 molar ratio) (Fig. 7A). It is currently accepted that rafts are the cellular equivalent of lo phase in vitro (38). The correlations between the area per lipid, the membrane thickness, anisotropy, and WT adhesion highlighted the most significant correlation between anisotropy and adhesion. As expected for lo, fewer adhering flagellated bacteria were observed than with POPC only, due to the gel phase state of the bilayer. The coexistence of lo and Id phases improved adhesion of the WT. In the Id phase, the ternary lipid system exhibited no significant differences with respect to that with POPC only. However, except for the Id phase, nonflagellated bacteria were clearly less adherent. The fact that no significant difference was observed for Id when comparing the WT to the $\Delta$ fliC mutant can be attributed to the presence of other adhesins capable of binding to chol or PSM or to small rafts. These small rafts formed more transition sites between raft and nonraft domains and could have helped the bacteria adhere to GUVs (Fig. 7B). Correlations between WT adhesion and the parameters determined by MD and anisotropies gave the best result with the fluidity state, with a moderate negative correlation (Fig. 7C and D). These results substantiate the previous hypothesis concerning an ideal plasma 
membrane fluidity to increase bacterial adhesion to lipid vesicles. However, with the ternary lipid system, the membrane is not homogeneous, which provides different sizes of lipid rafts depending on the lipid proportion. lo is rich in chol and is considered pure raft, lo/ld contains large rafts ( $>75$ to $100 \mathrm{~nm}$ ), and ld forms small rafts (<20 nm) (39).

\section{DISCUSSION}

To reach the plasma membrane, bacterial flagella need to go through the mucus barrier, which is organized in two parts: an outer "loose" layer and an inner "firmly" attached layer (40-42). Different strategies can be used by enteropathogenic bacteria to overcome this barrier, such as the use of mucin-degrading enzymes $(43,44)$, near surface swimming and mucus breaches (45), and Shiga toxin (Stx) production by Shiga toxin-producing E. coli to damage the intestinal barrier (46). Until recently, only a few studies have paid attention to enteric pathogen infection and plasma membrane lipid content during host invasion (36). Most of the studies have focused on proteins as targets for bacterial adhesion (23). By studying the flagellum-driven bacterial adhesion on biomimetic lipid bilayer membranes, we evidenced that the flagella of EHEC fully exploit the lipid bilayer to adhere. This interaction was originally identified by thin-layer chromatography to occur with negatively charged phospholipids by using immobilized lipids and purified flagella, which are not physiologically organized (17). Likewise, Salmonella enterica serovar Typhimurium flagella were described to interact with pure cholesterol used to coat surfaces but not organized in the complex structure of a plasma membrane (47). However, recently, we found that methylated flagella of Salmonella Typhimurium facilitate bacterial adhesion to PC GUV and negatively affect adhesion on pure POPG GUV (18).

The present work illustrates that both flagellar motility and the size and resulting curvature of the lipid vesicles are important factors for optimal bacterial adhesion. Until now, the fatty acid composition was largely ignored, but this work reveals its key role. Fatty acid saturation strongly impacts membrane thickness and area per lipid; both parameters thus appear as important biomarkers of flagellar adhesion. In the presence of saturated fatty acid, flagellar adhesion is optimal and modulated by the head group moiety of the membrane lipids. Conversely, the presence of unsaturated fatty acids decreases bacterial adhesion (Fig. 5), an effect which is even stronger when using polyunsaturated fatty acids (PC 18:3, $\alpha$-linolenic acid), where almost no flagellar adhesion was observed. The effect of polyunsaturated fatty acids on flagellar adhesion was still relevant on more complex plasma membranes, which include proteins, such as a human cell line (Fig. 6). These results reflect a clear role of lipid packing on flagellar adhesion.

The computed bilayer parameters, obtained by MD simulations, such as membrane thickness and area per molecule, have been related to the membrane ordering and fluidity (48). A more fluid membrane exhibits less order and has a higher value of area per lipid molecule and lower value of membrane thickness (when comparing lipid chains of the same size). A global correlation between these two structural parameters and the fluidity state of the GUV bilayer showed a very high level of correlation with most of the bilayer compositions used in this study. In turn, these two parameters correlated with bacterial adhesion. Although not perfect because many other parameters are at stake, these two parameters provide a very good trend about the optimal conditions that increase, or not, bacterial adhesion. In other words, these two parameters, which can be computed at a relatively low computational cost, are easily obtained descriptors of the bacterial adhesion process. By adding a few other descriptors, we believe that we could establish a quantitative structure activity relationship (QSAR) that could predict flagellar adhesion with high robustness.

Ectothermic organisms incorporate fatty acids in phospholipids via a mechanism termed "homeoviscous adaptation" to have constant viscosities at the temperature of cell growth (49). It is only within the homeoviscous adaptation limits that the diet of organisms can influence the membrane lipid profile. In endothermic animals, the membrane composition has been thoroughly documented to be influenced by dietary 
fats in the erythrocyte plasma membrane and later in the liver, the brain, and other organs (50-53). However, the influence of dietary intake on plasma membrane composition depends on the type of fatty acids ingested. Omega- 3 and omega- 6 fatty acids are not produced in mammals due to the lack of ad hoc desaturases; therefore, humans must consume such fatty acids (54). In contrast, palmitic acid can be synthesized endogenously, and its quantity is controlled under normal physiological conditions in order to not affect the membrane properties (55). It is noteworthy that the incorporation of diet fatty acids into membranes is influenced by the omega-3/omega- 6 balance (56). To successfully invade hosts, EHEC (which cause invasive disease) and Salmonella Typhimurium (an invasive organism) require adhesion to the intestinal epithelium (2, 57). Again, this process depends on plasma membrane fatty acid composition controlled by the diet (58). The impact of polyunsaturated fatty acids on human health during bacterial infection focuses on inflammation. $\alpha$-Linolenic acid is converted in arachidonic acid-derived inflammatory eicosanoids (59-61). Omega-3 fatty acids are converted as well to bioactive mediators, termed specialized pro-resolving mediators, that actively reprogram the host immune response to limit inflammation (62). However, little is known about the biophysical impact on bacterial adhesion and colonization of these fatty acids of the plasma membrane (36). Our results support the idea that a fatty acid diet can affect human health and, more surprisingly, host susceptibility to enteric pathogens by influencing flagellar adhesion to the plasma membrane.

Recently, bacterial flagellar motility was described to help bacteria to reach preferred sites in host plasma membrane containing sphingolipid-rich domains (63). Our findings show that not only motility but also bacterial flagella per se, acting as an adhesin on lipids, help bacteria to reach their host cell targets. As lipid rafts are the most documented plasma membrane lipids involved in bacterial adhesion $(21,24)$, we investigated three different types of lipid rafts: lo, lo/ld, and Id, reflecting pure, large-, and small-size rafts, respectively (39). Pure and small rafts did not substantially facilitate flagellar adhesion, whereas large-size rafts promoted adhesion (Fig. 7). These results suggest that an optimal size of lipid rafts exists that allows flagellar adhesion, which is consistent with previous works describing lipid rafts and bacterial adhesion $(21,24)$.

While our results highlight a previously unrecognized advantage of flagellated bacteria over bacteria lacking flagella (such as Shigella spp. or Staphylococcus spp.) in host cell adhesion, the presence of flagellin can be deleterious by inducing the immune system (11). To avoid this major drawback, flagellated bacteria downregulate flagellin expression during the planktonic/sessile switch and host invasion leading to immune evasion $(64,65)$. Accordingly, it is reasonable to speculate that, for at least EHEC 0157:H7 and Salmonella Typhimurium (16), this risk is compensated for by the capacity of the flagella to facilitate adhesion of the bacteria to the host cell plasma membrane. The increased adhesive properties of flagellated bacteria might increase the capability of the bacteria to invade their host. Furthermore, a recent paper illustrated the possibility that enzymatic or other unknown functionalities can be incorporated into the D3 domain of flagellins (66). Future work to explore lipolytic flagellins or other functional properties associated with lipids in flagellated bacterial species will be needed.

\section{MATERIALS AND METHODS}

Bacterial growth and preparation. EHEC 0157:H7 TUV93-0 derived from strain EDL933 was used (67). The isogenic mutant $\triangle$ fliC and $\triangle m o t A$ strains were obtained as described previously (7). All strains were grown in lysogeny broth (LB) medium ( $1 \%$ [wt/vol] tryptone, $0.5 \%$ yeast extract, and $0.5 \% \mathrm{NaCl}$ ) overnight at $37^{\circ} \mathrm{C}$ and $100 \mathrm{rpm}$. Bacterial motility was subsequently checked at $37^{\circ} \mathrm{C}$ after $7 \mathrm{~h}$ on motility medium (1\% [wt/vol] tryptone, $0.33[\mathrm{wt} / \mathrm{vol}]$ agar, and $0.4 \%[\mathrm{wt} / \mathrm{vol}] \mathrm{NaCl})$. For all experiments, the overnight culture was centrifuged at $3,500 \times \mathrm{g}$ for $15 \mathrm{~min}$ at $20^{\circ} \mathrm{C}$, resuspended in HEPES-buffered saline solution (HEPES, $20 \mathrm{mM}$ [pH 7.4]; $\mathrm{NaCl}, 150 \mathrm{mM}$ ), and diluted to a final concentration of $10^{8} \mathrm{CFU} / \mathrm{ml}$.

Liposome preparation. GUVs were prepared according to polyvinyl alcohol (PVA)-assisted gentle hydration (68). A 5\% PVA solution (wt/wt) was prepared in water with $280 \mathrm{mM}$ sucrose and strongly stirred at $95^{\circ} \mathrm{C}$ until complete dissolution of the PVA. Two hundred microliters of PVA solution was spread manually on a cover glass with a needle and dried on a heating plate at $50^{\circ} \mathrm{C}$ for $30 \mathrm{~min}$. Five microliters 
of lipid (Avanti Polar Lipids) solution in chloroform at $3 \mathrm{mg} / \mathrm{ml}$ was subsequently deposited four times and spread until solvent evaporation. The residual solvent that could remain on the lipid-coated cover glass was evaporated under vacuum for at least $1 \mathrm{~h}$. To form a well on the cover glass slide, a ring was glued onto it, and $500 \mu \mathrm{l}$ of HEPES-buffered saline solution was added for hydration. After swelling for $1 \mathrm{~h}$ at room temperature, the giant unilamellar vesicles (GUVs) formed were either directly stored in a fridge or reengaged in hydration of another preparation to obtain a higher lipid concentration. Most of the GUV sizes were evaluated manually under a microscope (see Fig. S1 in the supplemental material).

Another method of formation can be applied in order to form vesicles with a smaller diameter: from large unilamellar vesicles (LUV) to small GUVs. The lipid solution in chloroform was dried under a nitrogen stream and then under vacuum for $2 \mathrm{~h}$ to remove remaining solvent. The film was hydrated to the desired lipid concentration in HEPES-buffered saline solution. After vortexing, the multilamellar vesicle suspension was extruded 25 times using a syringe-type extruder with a polycarbonate filter having a pore size of $400 \mathrm{~nm}$ for $400-\mathrm{nm}$ liposomes, $2 \mu \mathrm{m}$ for $1-\mu \mathrm{m}$ liposomes, and $5 \mu \mathrm{m}$ for $2-\mu \mathrm{m}$ liposomes (Liposofast; Avestin Inc.). Prior to the extrusion for 400-nm liposomes, the solution was sonicated using a tip sonicator (Vibra-Cell ultrasonic processor; Sonic Materials). Liposome size was determined either manually with ImageJ by epifluorescence microscopy or by dynamic light scattering (Zetasizer Nano ZS; Malvern Instruments) for liposomes with a diameter smaller than $1 \mu \mathrm{m}$.

Labeling and epifluorescence microscopy. Liposomes were first immobilized on gold-coated glass. Prior to liposome preparation, 1,2-distearoyl-sn-glycero-3-phosphoethanolamine (DSPE)-polyethylene glycol (PEG)-N-[3-(2-(pyridyldithio)propionate (PDP) (Avanti Polar Lipids) was added to the lipid mixture in chloroform at $3 \%$ and was as well doped with 2 mol\% NBD-PE for liposome labeling (Avanti Polar Lipids). At the same time, a coverslip was coated with $1 \mathrm{~nm}$ of chromium and $10 \mathrm{~nm}$ of gold by thermal evaporation (Evaporator Edwards model Auto 306). The incubation between liposomes and bacteria was performed in a separated container for $1 \mathrm{~h}$ and transferred onto a microscope chamber. The latter was composed of the gold-coated glass surface at the bottom, spaced from a common microscope slide with lateral spacers of molten Parafilm. Observation was carried out on a Leica DMI6000 B epifluorescence microscope.

Bacterial adhesion assays on liposomes. Bacterial adhesion assays were performed in 6-well plates $\left(9.6 \mathrm{~cm}^{2}\right.$ per well). Gold-coated slides of $1.9 \mathrm{~cm}$ by $2.5 \mathrm{~cm}$ were placed onto a $3-\mathrm{mm}$-high pedestal in each well. One milliliter of $5 \mu \mathrm{g} / \mathrm{ml}$ liposome solution containing DSPE-PEG-PDP was homogeneously deposited on the gold-coated surface and incubated for $1 \mathrm{~h}$. After adding $10 \mathrm{ml}$ of HEPES-buffered saline solution, the pedestal was carefully removed with a bended pipette tip. A volume of $8 \mathrm{ml}$ was then removed to eliminate nonimmobilized liposomes with a minimal volume, to keep immerged the gold-coated surface. The immobilized liposomes were incubated for $1 \mathrm{~h}$ with $5 \mathrm{ml}$ of bacterial suspension at $10^{8} \mathrm{CFU} / \mathrm{ml}$ in HEPES-buffered saline. Prior to discarding all of the medium, the excess bacteria were removed by taking away $5 \mathrm{ml}$, and the nonadherent bacteria were removed from the wells with $8 \mathrm{ml}$ of fresh HEPES-buffered saline. With $1 \mathrm{ml}$ of phosphate-buffered saline (PBS), adherent bacteria were detached by pipetting vigorously several times directly onto the gold-coated surface. Samples were serially diluted and plated on LB agar for viable bacterial counts. The bacterial count for $0 \mu \mathrm{g}$ of lipid corresponds to the nonspecific bacterial adhesion to the gold surface without lipids. The nonspecific adhesion of a well alone (without glass and lipids) from the 6-well cell culture plate used to perform the assay was systematically subtracted. All adherence assays were performed at $23 \pm 2^{\circ} \mathrm{C}$ and at $4^{\circ} \mathrm{C}$ for DOPC ( $\Delta 9$-trans).

Bacterial adhesion assays on HT-29. The human colonic cell line HT-29 was obtained from the American Tissue Culture Collection (ATCC). The cell line was maintained in modified McCoy medium supplemented with $10 \%$ ( $\mathrm{vol} / \mathrm{vol})$ heat-inactivated fetal calf serum, $2 \mathrm{mM}$ L-glutamine, $100 \mathrm{U} / \mathrm{ml}$ penicillin, and $100 \mathrm{U} / \mathrm{ml}$ streptomycin at $37^{\circ} \mathrm{C}$ in $5 \% \mathrm{CO}_{2}$. Cultures were used between passages 15 to 20 . The cells were seeded in 24 -well culture plates $\left(1.9 \mathrm{~cm}^{2}\right.$ per well) at a concentration of $4 \times 10^{4}$ cells per well. The culture medium was changed every day. After $24 \mathrm{~h}$, the cells were treated with $100 \mu \mathrm{M} \mathrm{C}_{18: 3}$ $\left(\alpha\right.$-linolenic acid), $C_{16: 0}$ (palmitic acid) solubilized in ethanol, or only ethanol as a control. After $24 \mathrm{~h}$, the supernatant was removed, and $2 \times 10^{7}$ bacteria in $250 \mu \mathrm{l}$ PBS were incubated for $30 \mathrm{~min}$ at $37^{\circ} \mathrm{C}$. Then the cells were rinsed twice with PBS and treated with trypsin-EDTA. After sample dilution, samples were plated on LB agar for viable bacterial counts.

Laurdan generalized polarization measurements. One millimolar laurdan (Sigma-Aldrich) solution in dimethyl sulfoxide (DMSO) was added to the vesicle suspension in order to have a lipid/probe ratio of 20:1. This mixture was incubated in the dark for $30 \mathrm{~min}$ and further diluted in HEPES-buffered saline to a final concentration of $5 \mu \mathrm{M}$ laurdan and $100 \mu \mathrm{M}$ phospholipids. Flagella were purified as previously described by mechanical shearing (17). Increasing quantities of $\mathrm{H} 7$ flagella were progressively added to the laurdan/liposome mixture and incubated each time in the dark for $20 \mathrm{~min}$ in a circulating water bath at $37^{\circ} \mathrm{C}$. Generalized polarization (GP) (23) was calculated from the emission intensities at $440 \mathrm{~nm}$ and $490 \mathrm{~nm}$ after excitation at $390 \mathrm{~nm}$, according to the following equation (1):

$$
\mathrm{GP}=\frac{I_{440}-I_{490}}{I_{440}+I_{490}}
$$

using a Varian Cary Eclipse fluorescence spectrophotometer (Agilent Technologies). The relative $\triangle \mathrm{GP}$ was obtained by subtracting the GP value in the absence of flagella from all GP values, for each size of liposome.

Fluorescence anisotropy measurements. Steady-state fluorescence emission anisotropy $(r)$ was measured with a Cary Eclipse fluorescence spectrophotometer (Agilent Technologies) equipped with a thermostated cuvette holder. GUVs with an average diameter of $2 \mu \mathrm{m}$ and made of different lipid 
mixtures were prepared from a lipid dried film by extrusion as previously described. The fluorescent probes 1,6-diphenyl-1,3,5-hexatriene (DPH) or laurdan fluorescent probes (Sigma-Aldrich) were added prior the lipid film formation at the lipid/probe molar ratio of 40:1. The GUVs were diluted in HEPESbuffered saline (HBS) solution to the final concentration of $200 \mu \mathrm{M}$ lipids and $5 \mu \mathrm{M}$ fluorescent probes in the quartz cuvette and were incubated at the desired temperature for $30 \mathrm{~min}$ in the dark prior to fluorescence measurement. Fluorescence intensities were collected at $435 \mathrm{~nm}$ for DPH and for laurdan with excitation wavelengths 357 and $360 \mathrm{~nm}$, respectively. Anisotropy was automatically calculated by the software of the spectrophotometer according to equation (2):

$$
r=\frac{I_{0}-G I_{90}}{I_{0}+2 G I_{90}}
$$

where $I_{0}$ is the fluorescence intensity measured with polarizer in parallel orientation $\left(0^{\circ}\right)$ and $I_{90}$ is the intensity in perpendicular orientation (excitation $0^{\circ}$ and emission $90^{\circ}$ ). $G$ is the correction factor derived from the ratio of emission intensity at $0^{\circ}$ and $90^{\circ}$ with the excitation polarizer at $90^{\circ}$ and considering the different sensitivities of the detection system for vertically and horizontally polarized light (equation 3 ):

$$
G=\frac{I_{90}}{I_{0}}
$$

NMR for lipid ratio calculation in GUVs. High resolution ${ }^{1} \mathrm{H}$ spectra were recorded on a Bruker AVIII nuclear magnetic resonance (NMR) spectrometer equipped with a $5 \mathrm{~mm}$ broad-band fluorine observation (BBFO) probe head operating at $400 \mathrm{MHz}{ }^{1} \mathrm{H}$ Larmor frequency. All experiments were carried out at room temperature. The instrument's standard pulse sequence program (zg30) was used with the following parameters: 2-s acquisition time, 20-ppm spectral width, and 5-s relaxation delay. Deuterated chloroform and $5 \mathrm{~mm}$ NMR tubes were purchased from Eurisotop (Saint-Aubin, France). In total, 3,072 repetition experiments were performed leading to a total acquisition time of $6 \mathrm{~h}$. After data processing and phase and baseline corrections, the areas of the peaks of interest were determined by integration, and the molar ratio of lipids was calculated with relative integrations.

GC-FID. Fatty acids from seeds, seedlings, and plant tissues were directly transmethylated as described before (69). Heptadecanoic acid $\left(C_{17: 0}\right)$ was used as an internal standard. Fatty acid methyl esters were extracted in heptane and separated by gas chromatography with flame ionization detection.

Lipid extraction. The fatty acid content of the cells or GUVs was determined after extraction with a modified method according to Bligh and Dyer (70). Three hundred seventy-five microliters of a mixture of chloroform/methanol (2:1 [vol/vol]) containing butylated hydroxytoluene (BHT; $1 \mathrm{mM}$ ) was added to $100 \mu \mathrm{l}$ of aqueous solution containing lipid vesicles or cells. The mix was vortexed for 10 to $15 \mathrm{~min}$, and then $125 \mu \mathrm{l}$ of chloroform was added and mixed for $1 \mathrm{~min}$, followed by $125 \mu \mathrm{l}$ of water before centrifuging quickly. The lower phase was collected, dried under a stream of nitrogen at room temperature, and kept at $-20^{\circ} \mathrm{C}$ until needed for liquid chromatography-high-resolution tandem mass spectrometry (LC-HRMS ${ }^{2}$ ) analyses.

LC-HRMS 2 analyses. The lipids were resuspended in $200 \mu \mathrm{l}$ of isopropanol. LC was performed based on a modified protocol from reference 71. Briefly, a high-performance liquid chromatograph (HPLC) 1290 (Agilent Technologies) with a $C_{18}$ Hypersil gold column (100 mm by $2.1 \mathrm{~mm}, 1.9 \mu \mathrm{m}$; Thermo Fisher) at $50^{\circ} \mathrm{C}$ was used. Mobile phases were $60: 40$ ( vol $\left./ \mathrm{vol}\right)$ acetonitrile to water with 10 $\mathrm{mM}$ ammonium formate and $0.1 \%$ formic acid (solvent A) and 90:8:2 ( $\mathrm{vol} / \mathrm{vol} / \mathrm{vol}$ ) isopropanol to acetonitrile to water with $10 \mathrm{mM}$ ammonium formate and $0.1 \%$ formic acid (solvent B). The gradient was as follows: A, 0 to $2 \mathrm{~min}, 68 \%$; 2 to $8 \mathrm{~min}, 60 \%$; 8 to $10 \mathrm{~min}, 55 \%$; 10 to $16 \mathrm{~min}, 50 \%$; 16 to $22 \mathrm{~min}$, $40 \%$; 22 to $28 \mathrm{~min}, 30 \%$; 28 to $35 \mathrm{~min}, 20 \%$; 35 to $40 \mathrm{~min}, 0 \%$. Finally, the column was equilibrated for $6 \mathrm{~min}$ with $68 \%$. The flow rate was set at $0.25 \mathrm{ml} / \mathrm{min}$ and with an injection volume of $2 \mu \mathrm{l}$. LC-electrospray ionization (ESI)-HRMS 2 analyses were achieved by coupling the LC system to a hybrid quadrupole time of flight (QTOF) mass spectrometer Agilent 6538 (Agilent Technologies) equipped with dual electrospray ionization (ESI). The source temperature, fragmentor, and the skimmer were set up at $350^{\circ} \mathrm{C}, 150 \mathrm{~V}$, and $65 \mathrm{~V}$, respectively. The acquisition was made in full scan mode between $100 \mathrm{~m} / \mathrm{z}$ and $1,700 \mathrm{~m} / \mathrm{z}$, with a scan of 2 spectra per s. Selected parent ions were fragmented with collision energy fixed at $35 \mathrm{eV}$. MS' scans were performed on the sixth most intense ions. Two internal reference masses were used for in-run calibration of the mass spectrometer (121.0509 and 922.0098 in positive-ion mode and 112.9856 and 1033.9881 in negative-ion mode). MassHunter B.07 software enabled the control of the parameters of the machine and acquired and processed the data. The mass spectra were acquired in positive- and negative-ion modes.

Data processing and annotation. Agilent generated files ( $\left.{ }^{*} . \mathrm{d}\right)$ were converted to *.mzXML format using MSConvert (72). File ( $\left.{ }^{*} \cdot \mathrm{mzXML}\right)$ data sets were processed using MZmine 2 v2.37 (73). The noise level was 2.0E3 for $\mathrm{MS}^{1}$ and $0 \mathrm{E} 00$ for $\mathrm{MS}^{2}$ in centroid. The chromatogram builder was used with a minimum time span of $0.10 \mathrm{~min}$, a minimum of height of $1.0 \mathrm{E} 3$ and $\mathrm{m} / \mathrm{z}$ tolerance of $5 \mathrm{ppm}$. The chromatogram deconvolution was conducted with the local minimum search algorithm. The chromatographic threshold was $30.0 \%$; the search minimum in retention time (RT) range was 0.05 min with a minimum relative height of $5 \%$ and a minimum ratio of peak top/edge of 2 . Peak duration range 0.05 to $3 \mathrm{~min}$. $\mathrm{MS}^{2} \mathrm{scans}$ were paired using an $\mathrm{m} / \mathrm{z}$ tolerance range of $0.05 \mathrm{Da}$ and RT tolerance range of $0.1 \mathrm{~min}$. Isotopologues were grouped using the isotopic peaks grouper algorithm with an $\mathrm{m} / \mathrm{z}$ tolerance of 0.008 and an RT tolerance of $0.3 \mathrm{~min}$. A peak alignment step was performed using the join aligner module $(\mathrm{m} / \mathrm{z}$ tolerance $=0.008$, weight for $\mathrm{m} / \mathrm{z}=50$, weight for $\mathrm{RT}=50$, absolute RT tolerance $=2 \mathrm{~min}$ ). Peak finder module was used with an intensity tolerance of $10 \%, \mathrm{~m} / \mathrm{z}$ tolerance of 0.008 , and retention time tolerance of $1.0 \mathrm{~min}$. The resulting peak list was then filtered using the peak list row filter module with a minimum 
peak in a row of 2, a minimum peak in an isotope pattern of 2 , and by keeping only peaks with $\mathrm{MS}^{2}$ scan (GNPS). The peak list was then exported to *.csv using the module "Export to CSV file." Moreover, an *mgf file was exported using the module "export for/submit to GNPS." The peak list was annotated using a combination of four databases, GNPS (74), lipid blast (75), lipid match (76), and lipiDex (77). Nonannotated features were removed.

MD simulations. POPC and DOPC lipid bilayers were composed of 128 lipid molecules in total and were put into a hydrated simulation box, as generated by the CHARMM-GUI membrane builder (78). The mixtures (POPC/POPE, POPC/POPG, POPC/DOPC, POPC/DOPE, and POPC/DOPG) were prepared accordingly, except that a 38:26 ratio was used in each leaflet to create the desired 40:60 molar ratios. To simulate the properties of the PC 18:3 membrane, the PC $C_{18: 2} / C_{18: 3}$ lipid was selected as being structurally close in terms of lipid tails and similar in the head group and because this lipid has already been parameterized in the Charmm force-field, whereas PC 18:3 has not. In the simulations with sphingomyelin, the POPC/PSM/CHOL ratios were 21:22:21 for the simulation with equal ratios, 16:23:25 for the ordered phase, and 43:14:4 for the disordered phase. One hundred fifty millimolar $\mathrm{NaCl}$ plus ions necessary for system charge neutralization were added to the simulation box to model the ion physiological concentration. The CHARMM-GUI Charmm force field topology and parameter files were transferred to the amber format using parmed. The systems were minimized using the steepest gradient for 500 steps and conjugate gradient for 500 steps with the lipid molecules restrained, followed by minimizing and heating. The production simulation was run for $500 \mathrm{~ns}$ at $293.15 \mathrm{~K}$, using the Amber 18 software package (79), the Charmm36 forcefield for lipids and the TIP3P model for water (80), and with a time step of $2 \mathrm{fs}$. The SHAKE algorithm was used for hydrogen atoms (81). The Langevin thermostat and constant pressure periodic boundary conditions with anisotropic pressure coupling in the $x y$ direction were applied. The last $200 \mathrm{~ns}$ of each simulation was used to calculate all parameters (area per lipid, membrane thickness, and order parameters) as well as related standard deviations.

Statistical analysis. For bacterial adhesion assays, the means \pm standard errors (SEs) were calculated from values obtained from five replicates and performed with at least three independent biological experiments. Three assays were carried out for lipid analysis. Statistical evaluation was performed with GraphPad Prism (GraphPad Software, San Diego, CA). The statistical significance was evaluated with Student's $t$ test or one-way analysis of variance. The heatmap was performed on Metaboanalyst (82). The results were considered significant for a $P$ value of $\leq 0.05$. Secondary data analysis and correlation matrices were calculated using the open-source software GNU-R. Bacterial growth counts across all the tested scenarios as well as metrics related to each lipid composition (viz. membrane thickness, area per molecule, and DPH and laurdan anisotropy) were loaded as csv files into the R environment. Correlations were computed using the "corr" function of the R library "Hmisc," which calculates the significance level $(P$ value) using Pearson correlation coefficient on raw values. The correlation matrix plots were generated using the R packages "corrplot" and "PerformanceAnalytics." To interpret the size of the correlation coefficient, it was as follows as described previously (83): 1.00 to 0.9 , very high; 0.9 to 0.7 , high; 0.7 to 0.5 , moderate; 0.5 to 0.3 , low; 0.3 to 0 , negligible correlation.

\section{SUPPLEMENTAL MATERIAL}

Supplemental material is available online only.

FIG S1, TIF file, $0.3 \mathrm{MB}$.

FIG S2, TIF file, 1.2 MB.

FIG S3, TIF file, $0.3 \mathrm{MB}$.

FIG S4, TIF file, 1.1 MB.

FIG S5, TIF file, 1.2 MB.

FIG S6, TIF file, 1.6 MB.

FIG S7, TIF file, $2.5 \mathrm{MB}$.

FIG S8, TIF file, $2.5 \mathrm{MB}$.

\section{ACKNOWLEDGMENTS}

We thank David Gally and Eliza Wolfson for Stx-negative derivative strain of TUV 93-0 and its isogenic mutants ( $\triangle$ fliC and $\triangle \operatorname{mot} A$ ). We also thank Ashleigh Holmes for her critical review and Muriel Vayssade for providing HT29 cell line.

This work was supported by the European Regional Development fund ERDF and the Region of Picardy (CPER 2007-2020) and the French Ministry of Higher Education, Research and Innovation (to H.C. and L.L.).

\section{REFERENCES}

1. Havelaar AH, Kirk MD, Torgerson PR, Gibb HJ, Hald T, Lake RJ, Praet N, Bellinger DC, de Silva NR, Gargouri N, Speybroeck N, Cawthorne A, Mathers C, Stein C, Angulo FJ, Devleesschauwer B, World Health Organization Foodborne Disease Burden Epidemiology Reference Group. 2015. World Health Organization global estimates and regional compar- isons of the burden of foodborne disease in 2010. PLoS Med 12: e1001923. https://doi.org/10.1371/journal.pmed.1001923.

2. Kaper JB, Nataro JP, Mobley HLT. 2004. Pathogenic Escherichia coli. Nat Rev Microbiol 2:123-140. https://doi.org/10.1038/nrmicro818.

3. Holden N, Pritchard L, Toth I. 2009. Colonization out with the colon: 
plants as an alternative environmental reservoir for human pathogenic enterobacteria: review article. FEMS Microbiol Rev 33:689-703. https:// doi.org/10.1111/j.1574-6976.2008.00153.x.

4. Bardiau M, Szalo M, Mainil JG. 2010. Initial adherence of EPEC, EHEC and VTEC to host cells. Vet Res 41:57. https://doi.org/10.1051/vetres/ 2010029.

5. Moon HW, Whipp SC, Argenzio RA, Levine MM, Giannella RA. 1983. Attaching and effacing activities of rabbit and human enteropathogenic Escherichia coli in pig and rabbit intestines. Infect Immun 41:1340-1351. https://doi.org/10.1128/IAI.41.3.1340-1351.1983.

6. Nougayrède J-P, Fernandes PJ, Donnenberg MS. 2003. Adhesion of enteropathogenic Escherichia coli to host cells. Cell Microbiol 5:359-372. https://doi.org/10.1046/j.1462-5822.2003.00281.x.

7. Wolfson EB, Elvidge J, Tahoun A, Gillespie T, Mantell J, McAteer SP, Rossez Y, Paxton E, Lane F, Shaw DJ, Gill AC, Stevens J, Verkade P, Blocker A, Mahajan A, Gally DL. 13 February 2020. Bacterial flagella disrupt host cell membranes and interact with cytoskeletal components. bioRxiv https://doi.org/10.1101/2020.02.12.945204.

8. Pizarro-Cerdá J, Cossart P. 2006. Bacterial adhesion and entry into host cells. Cell 124:715-727. https://doi.org/10.1016/j.cell.2006.02.012.

9. Kline KA, Fälker S, Dahlberg S, Normark S, Henriques-Normark B. 2009. Bacterial adhesins in host-microbe interactions. Cell Host Microbe 5:580 -592. https://doi.org/10.1016/j.chom.2009.05.011.

10. Haiko J, Westerlund-Wikström B. 2013. The role of the bacterial flagellum in adhesion and virulence. Biology (Basel) 2:1242-1267. https://doi.org/ 10.3390/biology2041242

11. Rossez Y, Wolfson EB, Holmes A, Gally DL, Holden NJ. 2015. Bacterial flagella: twist and stick, or dodge across the kingdoms. PLoS Pathog 11:e1004483. https://doi.org/10.1371/journal.ppat.1004483.

12. Erdem AL, Avelino F, Xicohtencatl-Cortes J, Girón JA. 2007. Host protein binding and adhesive properties of $\mathrm{H} 6$ and $\mathrm{H} 7$ flagella of attaching and effacing Escherichia coli. J Bacteriol 189:7426-7435. https://doi.org/10 1128/JB.00464-07.

13. Sourjik V, Wingreen NS. 2012. Responding to chemical gradients: bacterial chemotaxis. Curr Opin Cell Biol 24:262-268. https://doi.org/10 .1016/j.ceb.2011.11.008

14. Beatson SA, Minamino T, Pallen MJ. 2006. Variation in bacterial flagellins: from sequence to structure. Trends Microbiol 14:151-155. https://doi .org/10.1016/j.tim.2006.02.008.

15. Yonekura K, Maki-Yonekura S, Namba K. 2003. Complete atomic model of the bacterial flagellar filament by electron cryomicroscopy. Nature 424:643-650. https://doi.org/10.1038/nature01830.

16. O'Brien EJ, Bennett PM. 1972. Structure of straight flagella from a mutant Salmonella. J Mol Biol 70:133-152. https://doi.org/10.1016/0022-2836(72) 90168-4.

17. Rossez Y, Holmes A, Wolfson EB, Gally DL, Mahajan A, Pedersen HL, Willats WGT, Toth IK, Holden NJ. 2014. Flagella interact with ionic plant lipids to mediate adherence of pathogenic Escherichia coli to fresh produce plants. Environ Microbiol 16:2181-2195. https://doi.org/10 $1111 / 1462-2920.12315$

18. Horstmann JA, Lunelli M, Cazzola $H$, Heidemann J, Kühne $C$, Steffen $P$, Szefs S, Rossi C, Lokareddy RK, Wang C, Lemaire L, Hughes KT, Uetrecht C, Schlüter H, Grassl GA, Stradal TEB, Rossez Y, Kolbe M, Erhardt M. 2020. Methylation of Salmonella Typhimurium flagella promotes bacterial adhesion and host cell invasion. Nat Commun 11:2013. https://doi.org/10 .1038/s41467-020-15738-3.

19. Simons K, Ikonen E. 1997. Functional rafts in cell membranes. Nature 387:569-572. https://doi.org/10.1038/42408

20. Brown DA, London E. 1998. Functions of lipid rafts in biological membranes. Annu Rev Cell Dev Biol 14:111-136. https://doi.org/10 1146/annurev.cellbio.14.1.111.

21. Mañes S, Del Real G, Martínez-A C. 2003. Pathogens: raft hijackers. Nat Rev Immunol 3:557-568. https://doi.org/10.1038/nri1129.

22. Rogers TJ, Thorpe CM, Paton AW, Paton JC. 2012. Role of lipid rafts and flagellin in invasion of colonic epithelial cells by Shiga-toxigenic Escherichia coli 0113:H21. Infect Immun 80:2858-2867. https://doi.org/10.1128/IAI .00336-12.

23. Bagam P, Singh DP, Inda ME, Batra S. 2017. Unraveling the role of membrane microdomains during microbial infections. Cell Biol Toxicol 33:429-455. https://doi.org/10.1007/s10565-017-9386-9.

24. Lafont F, van der Goot FG. 2005. Bacterial invasion via lipid rafts. Cell Microbiol 7:613-620. https://doi.org/10.1111/j.1462-5822.2005.00515.x.

25. Parasassi T, De Stasio G, d'Ubaldo A, Gratton E. 1990. Phase fluctuation in phospholipid membranes revealed by laurdan fluorescence. Biophys J 57:1179-1186. https://doi.org/10.1016/S0006-3495(90)82637-0.

26. De Vequi-Suplicy CC, Benatti CR, Lamy MT. 2006. Laurdan in fluid bilayers: position and structural sensitivity. J Fluoresc 16:431-439. https://doi.org/10 .1007/s10895-005-0059-3.

27. Lipowsky R, Risselada HJ, Jahn R, Sykes C, Baumgart T, Frolov VA, Dimova $R$, Lauritsen L, Voth GA, Deserno M, Stamou D, Breuer A, Pucadyil TJ, Jin R, Bassereau P, Kozlov MM, Simon C, Johannes L, Zeno WF, Bashkirov PV Weikl TR, Stachowiak JC, Grubmüller H. 2018. The 2018 biomembrane curvature and remodeling roadmap. J Phys D Appl Phys 51:343001. https://doi.org/10.1088/1361-6463/aacb98.

28. Pera H, Kleijn JM, Leermakers FAM. 2012. Interaction of silica nanoparticles with phospholipid membranes. Chem Lett 41:1322-1324. https:// doi.org/10.1246/cl.2012.1322.

29. Harris FM, Best KB, Bell JD. 2002. Use of laurdan fluorescence intensity and polarization to distinguish between changes in membrane fluidity and phospholipid order. Biochim Biophys Acta 1565:123-128. https:// doi.org/10.1016/S0005-2736(02)00514-X

30. Israelachvili JN, Mitchell DJ, Ninham BW. 1976. Theory of self-assembly of hydrocarbon amphiphiles into micelles and bilayers. J Chem Soc Faraday Trans 2 72:1525-1568. https://doi.org/10.1039/f29767201525.

31. Marczak A. 2009. Fluorescence anisotropy of membrane fluidity probes in human erythrocytes incubated with anthracyclines and glutaraldehyde. Bioelectrochemistry 74:236-239. https://doi.org/10.1016/j.bioelechem.2008 .11 .004 .

32. Dickey A, Faller R. 2008. Examining the contributions of lipid shape and headgroup charge on bilayer behavior. Biophys J 95:2636-2646. https:// doi.org/10.1529/biophysj.107.128074

33. Rawicz W, Olbrich KC, McIntosh T, Needham D, Evans EA. 2000. Effect of chain length and unsaturation on elasticity of lipid bilayers. Biophys $J$ 79:328-339. https://doi.org/10.1016/S0006-3495(00)76295-3.

34. Spector A, Mathur S, Kaduce T. 1980. Lipid nutrition and metabolism of cultured mammalian cells. Prog Lipid Res 19:155-186. https://doi.org/10 .1016/0163-7827(80)90003-X

35. Murthy S, Albright E, Mathur SN, Field FJ. 1988. Modification of CaCo-2 cell membrane fatty acid composition by eicosapentaenoic acid and palmitic acid: effect on cholesterol metabolism. J Lipid Res 29:773-780.

36. Rossi C, Cazzola H, Holden NJ, Rossez Y. 2019. Bacterial adherence to plant and animal surfaces via adhesin-lipid interactions, p 1-21. Health consequences of microbial interactions with hydrocarbons, oils, and lipids. Springer International Publishing, Cham, Switzerland.

37. de Almeida RFM, Fedorov A, Prieto M. 2003. Sphingomyelin/phosphatidylcholine/cholesterol phase diagram: boundaries and composition of lipid rafts. Biophys J 85:2406-2416. https://doi.org/10.1016/S0006-3495 (03)74664-5.

38. London E, Brown DA. 2000. Insolubility of lipids in Triton X-100: physical origin and relationship to sphingolipid/cholesterol membrane domains (rafts). Biochim Biophys Acta 1508:182-195. https://doi.org/10.1016/S0304 -4157(00)00007-1.

39. De Almeida RFM, Loura LMS, Fedorov A, Prieto M. 2005. Lipid rafts have different sizes depending on membrane composition: a time-resolved fluorescence resonance energy transfer study. J Mol Biol 346 1109-1120. https://doi.org/10.1016/j.jmb.2004.12.026.

40. Atuma C, Strugala V, Allen A, Holm L. 2001. The adherent gastrointestinal mucus gel layer: thickness and physical state in vivo. Am J Physiol Gastrointest Liver Physiol 280:G922-G929. https://doi.org/10 1152/ajpgi.2001.280.5.G922.

41. Swidsinski A, Weber J, Loening-Baucke V, Hale LP, Lochs H. 2005. Spatia organization and composition of the mucosal flora in patients with inflammatory bowel disease. J Clin Microbiol 43:3380-3389. https://doi .org/10.1128/JCM.43.7.3380-3389.2005

42. Johansson MV, Phillipson M, Petersson J, Velcich A, Holm L, Hansson GC. 2008. The inner of the two Muc2 mucin-dependent mucus layers in colon is devoid of bacteria. Proc Natl Acad Sci U S A 105:15064-15069. https://doi.org/10.1073/pnas.0803124105.

43. Luo T, Mohan K, Iglesias P, Robinson D. 2013. Molecular mechanisms of cellular mechanosensing. Nat Mater 12:1064-1071. https://doi .org/10.1038/nmat3772.

44. Kumar P, Luo Q, Vickers TJ, Sheikh A, Lewis WG, Fleckenstein JM. 2014. Eat $A$, an immunogenic protective antigen of enterotoxigenic Escherichia coli, degrades intestinal mucin. Infect Immun 82:500-508. https://doi org/10.1128/IAI.01078-13.

45. Furter M, Sellin ME, Hansson GC, Hardt W-D. 2019. Mucus architecture and near-surface swimming affect distinct Salmonella Typhimurium infection 
patterns along the murine intestinal tract. Cell Rep 27:2665.e3-2678.e3. https://doi.org/10.1016/j.celrep.2019.04.106.

46. Menge C. 2020. Molecular biology of Escherichia coli Shiga toxins' effects on mammalian cells. Toxins (Basel) 12:345. https://doi.org/10 .3390/toxins 12050345 .

47. Crawford RW, Reeve KE, Gunn JS. 2010. Flagellated but not hyperfimbriated Salmonella enterica serovar Typhimurium attaches to and forms biofilms on cholesterol-coated surfaces. J Bacteriol 192:2981-2990. https://doi.org/10.1128/JB.01620-09.

48. Reddy AS, Warshaviak DT, Chachisvilis M. 2012. Effect of membrane tension on the physical properties of DOPC lipid bilayer membrane. Biochim Biophys Acta 1818:2271-2281. https://doi.org/10.1016/j .bbamem.2012.05.006.

49. Sinensky M. 1974. Homeoviscous adaptation-a homeostatic process that regulates the viscosity of membrane lipids in Escherichia coli. Proc Natl Acad Sci U S A 71:522-525. https://doi.org/10.1073/pnas.71 .2 .522 .

50. Ibarguren M, López DJ, Escribá PV. 2014. The effect of natural and synthetic fatty acids on membrane structure, microdomain organization, cellular functions and human health. Biochim Biophys Acta 1838: 1518-1528. https://doi.org/10.1016/j.bbamem.2013.12.021.

51. Farquhar JW, Ahrens EH. 1963. Effects of dietary fats on human erythrocyte fatty acid patterns. J Clin Invest 42:675-685. https://doi.org/10 $.1172 / \mathrm{JCl} 104759$.

52. Kinsella JE. 1990. Lipids, membrane receptors, and enzymes: effects of dietary fatty acids. JPEN J Parenter Enteral Nutr 14:200S-217S. https:// doi.org/10.1177/014860719001400511.

53. Stubbs CD, Smith AD. 1984. The modification of mammalian membrane polyunsaturated fatty acid composition in relation to membrane fluidity and function. Biochim Biophys Acta 779:89-137. https://doi.org/10 .1016/0304-4157(84)90005-4.

54. Nakamura MT, Nara TY. 2004. Structure, function, and dietary regulation of $\Delta 6, \Delta 5$, and $\Delta 9$ desaturases. Annu Rev Nutr 24:345-376. https://doi .org/10.1146/annurev.nutr.24.121803.063211.

55. Carta G, Murru E, Banni S, Manca C. 2017. Palmitic acid: physiological role, metabolism and nutritional implications. Front Physiol 8:902. https://doi.org/10.3389/fphys.2017.00902.

56. Abbott SK, Else PL, Atkins TA, Hulbert AJ. 2012. Fatty acid composition of membrane bilayers: importance of diet polyunsaturated fat balance. Biochim Biophys Acta 1818:1309-1317. https://doi.org/10.1016/j.bbamem 2012.01.011.

57. Velge $P$, Wiedemann A, Rosselin M, Abed N, Boumart Z, Chaussé AM, Grépinet O, Namdari F, Roche SM, Rossignol A, Virlogeux-Payant I. 2012. Multiplicity of Salmonella entry mechanisms, a new paradigm for Salmonella pathogenesis. Microbiologyopen 1:243-258. https://doi.org/10 $.1002 / \mathrm{mbo3} .28$.

58. Alessandri JM, Joannie JL, Durand GA. 1993. Polyunsaturated fatty acids as differentiation markers of rat jejunal epithelial cells: a modeling approach. J Nutr Biochem 4:97-104. https://doi.org/10.1016/0955-2863(93) 90007-J.

59. Calder PC. 2009. Polyunsaturated fatty acids and inflammatory processes: new twists in an old tale. Biochimie 91:791-795. https://doi .org/10.1016/j.biochi.2009.01.008.

60. Husson MO, Ley D, Portal C, Gottrand M, Hueso T, Desseyn JL, Gottrand F. 2016. Modulation of host defence against bacterial and viral infections by omega-3 polyunsaturated fatty acids. J Infect 73:523-535. https://doi .org/10.1016/j.jinf.2016.10.001.

61. Barceló-Coblijn G, Murphy EJ. 2009. Alpha-linolenic acid and its conversion to longer chain n-3 fatty acids: benefits for human health and a role in maintaining tissue n-3 fatty acid levels. Prog Lipid Res 48:355-374. https://doi.org/10.1016/j.plipres.2009.07.002.

62. Bannenberg G, Serhan CN. 2010. Specialized pro-resolving lipid mediators in the inflammatory response: an update. Biochim Biophys Acta 1801:1260-1273. https://doi.org/10.1016/j.bbalip.2010.08.002.

63. Tawk C, Nigro G, Rodrigues Lopes I, Aguilar C, Lisowski C, Mano M, Sansonetti P, Vogel J, Eulalio A. 2018. Stress-induced host membrane remodeling protects from infection by non-motile bacterial pathogens. EMBO J 37:e98529. https://doi.org/10.15252/embj.201798529.

64. Belas R. 2014. Biofilms, flagella, and mechanosensing of surfaces by bacteria. Trends Microbiol 22:517-527. https://doi.org/10.1016/j.tim .2014.05.002.

65. Bergman MA, Cummings LA, Barrett SLR, Smith KD, Lara JC, Aderem A, Cookson BT. 2005. CD4 ${ }^{+}$T cells and Toll-like receptors recognize Salmonella antigens expressed in bacterial surface organelles. Infect
Immun 73:1350-1356. https://doi.org/10.1128/IAI.73.3.1350-1356 .2005 .

66. Eckhard U, Bandukwala H, Mansfield MJ, Marino G, Cheng J, Wallace I, Holyoak T, Charles TC, Austin J, Overall CM, Doxey AC. 2017. Discovery of a proteolytic flagellin family in diverse bacterial phyla that assembles enzymatically active flagella. Nat Commun 8:521. https://doi.org/10 .1038/s41467-017-00599-0.

67. Perna NT, Plunkett G, Burland V, Mau B, Glasner JD, Rose DJ, Mayhew GF, Evans PS, Gregor J, Kirkpatrick HA, Pósfai G, Hackett J, Klink S, Boutin A, Shao Y, Miller L, Grotbeck EJ, Davis NW, Lim A, Dimalanta ET, Potamousis KD, Apodaca J, Anantharaman TS, Lin J, Yen G, Schwartz DC, Welch RA, Blattner FR. 2001. Genome sequence of enterohaemorrhagic Escherichia coli 0157:H7. Nature 409:529-533. https://doi.org/10.1038/35054089.

68. Weinberger A, Tsai FC, Koenderink GH, Schmidt TF, Itri R, Meier W, Schmatko T, Schröder A, Marques C. 2013. Gel-assisted formation of giant unilamellar vesicles. Biophys J 105:154-164. https://doi.org/10.1016/j.bpj 2013.05.024.

69. Nguyen PJ, Rippa S, Rossez Y, Perrin Y. 2016. Acylcarnitines participate in developmental processes associated to lipid metabolism in plants. Planta 243:1011-1022. https://doi.org/10.1007/s00425-016-2465-y.

70. Bligh EG, Dyer WJ. 1959. A rapid method of total lipid extraction and purification. Can J Biochem Physiol 37:911-917. https://doi.org/10.1139/ 059-099.

71. Ulmer CZ, Patterson RE, Koelmel JP, Garrett TJ, Yost RA. 2017. A robust lipidomics workflow for mammalian cells, plasma, and tissue using liquid-chromatography high-resolution tandem mass spectrometry, $p$ 91-106. In Bhattacharya SK (ed), Methods in molecular biology 1609. Springer, New York, NY.

72. Chambers MC, Maclean B, Burke R, Amodei D, Ruderman DL, Neumann S, Gatto L, Fischer B, Pratt B, Egertson J, Hoff K, Kessner D, Tasman N, Shulman N, Frewen B, Baker TA, Brusniak M-Y, Paulse C, Creasy D, Flashner L, Kani K, Moulding C, Seymour SL, Nuwaysir LM, Lefebvre B, Kuhlmann F, Roark J, Rainer P, Detlev S, Hemenway T, Huhmer A, Langridge J, Connolly B, Chadick T, Holly K, Eckels J, Deutsch EW, Moritz RL, Katz JE, Agus DB, MacCoss M, Tabb DL, Mallick P. 2012. A crossplatform toolkit for mass spectrometry and proteomics. Nat Biotechnol 30:918-920. https://doi.org/10.1038/nbt.2377.

73. Pluskal T, Castillo S, Villar-Briones A, Orešič M. 2010. MZmine 2: modular framework for processing, visualizing, and analyzing mass spectrometrybased molecular profile data. BMC Bioinformatics 11:395. https://doi .org/10.1186/1471-2105-11-395.

74. Wang M, Carver JJ, Phelan VV, Sanchez LM, Garg N, Peng Y, Nguyen DD, Watrous J, Kapono CA, Luzzatto-Knaan T, Porto C, Bouslimani A, Melnik AV, Meehan MJ, Liu WT, Crüsemann M, Boudreau PD, Esquenazi $E$, Sandoval-Calderón $M$, Kersten RD, Pace LA, Quinn RA, Duncan KR, Hsu CC, Floros DJ, Gavilan RG, Kleigrewe K, Northen T, Dutton RJ, Parrot D, Carlson EE, Aigle B, Michelsen CF, Jelsbak L, Sohlenkamp C, Pevzner P, Edlund A, McLean J, Piel J, Murphy BT, Gerwick L, Liaw CC, Yang YL, Humpf HU, Maansson M, Keyzers RA, Sims AC, Johnson AR, Sidebottom AM, Sedio BE, et al. 2016. Sharing and community curation of mass spectrometry data with global natural products social molecular networking. Nat Biotechnol 34: 828-837. https://doi.org/10.1038/nbt.3597.

75. Kind T, Liu K-H, Lee DY, DeFelice B, Meissen JK, Fiehn O. 2013. LipidBlast in silico tandem mass spectrometry database for lipid identification. Nat Methods 10:755-758. https://doi.org/10.1038/nmeth.2551.

76. Koelmel JP, Kroeger NM, Ulmer CZ, Bowden JA, Patterson RE, Cochran JA, Beecher CWW, Garrett TJ, Yost RA. 2017. LipidMatch: an automated workflow for rule-based lipid identification using untargeted highresolution tandem mass spectrometry data. BMC Bioinformatics 18:1-11. https://doi.org/10.1186/s12859-017-1744-3.

77. Hutchins PD, Russell JD, Coon JJ. 2018. LipiDex: an integrated software package for high-confidence lipid identification. Cell Syst 6:621.e5-625.e5. https://doi.org/10.1016/j.cels.2018.03.011.

78. Lee J, Patel DS, Ståhle J, Park SJ, Kern NR, Kim S, Lee J, Cheng X, Valvano MA, Holst O, Knirel YA, Qi Y, Jo S, Klauda JB, Widmalm G, Im W. 2019. CHARMM-GUI membrane builder for complex biological membrane simulations with glycolipids and lipoglycans. J Chem Theory Comput 15: 775-786. https://doi.org/10.1021/acs.jctc.8b01066.

79. Case DA, Cheatham TE, Darden T, Gohlke H, Luo R, Merz KM, Onufriev A, Simmerling C, Wang B, Woods RJ. 2005. The Amber biomolecular simulation programs. J Comput Chem 26:1668-1688. https://doi.org/10.1002/jcc.20290.

80. Jorgensen WL, Chandrasekhar J, Madura JD, Impey RW, Klein ML. 1983. 
Comparison of simple potential functions for simulating liquid water. J Chem Phys 79:926-935. https://doi.org/10.1063/1.445869.

81. Ryckaert JP, Ciccotti G, Berendsen HJC. 1977. Numerical integration of the cartesian equations of motion of a system with constraints: molecular dynamics of $n$-alkanes. J Comput Phys 23:327-341. https://doi.org/ 10.1016/0021-9991(77)90098-5.

82. Pang Z, Chong J, Li S, Xia J. 2020. MetaboanalystR 3.0: toward an optimized workflow for global metabolomics. Metabolites 10:186. https://doi.org/10 .3390/metabo10050186.

83. Mukaka MM. 2012. Statistics corner: a guide to appropriate use of correlation coefficient in medical research. Malawi Med J 24:69-71.

84. Koynova R, Caffrey M. 1998. Phases and phase transitions of the phosphatidylcholines. Biochim Biophys Acta 1376:91-145. https://doi.org/10 .1016/S0304-4157(98)00006-9. 